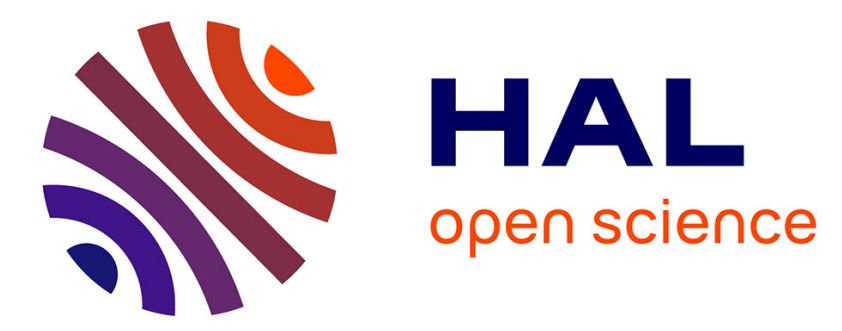

\title{
The narrow-spectrum anthelmintic oxantel is a potent agonist of a novel acetylcholine receptor subtype in whipworms
}

Tina Hansen, Susanna Cirera, Cédric Neveu, Elise Courtot, Claude Charvet, Kirstine Calloe, Dan Klaerke, Richard Martin

\section{To cite this version:}

Tina Hansen, Susanna Cirera, Cédric Neveu, Elise Courtot, Claude Charvet, et al.. The narrowspectrum anthelmintic oxantel is a potent agonist of a novel acetylcholine receptor subtype in whipworms. PLoS Pathogens, 2021, 17 (2), 26 p. 10.1371/journal.ppat.1008982 . hal-03148568

\section{HAL Id: hal-03148568 \\ https://hal.science/hal-03148568}

Submitted on 24 Jun 2021

HAL is a multi-disciplinary open access archive for the deposit and dissemination of scientific research documents, whether they are published or not. The documents may come from teaching and research institutions in France or abroad, or from public or private research centers.
L'archive ouverte pluridisciplinaire HAL, est destinée au dépôt et à la diffusion de documents scientifiques de niveau recherche, publiés ou non, émanant des établissements d'enseignement et de recherche français ou étrangers, des laboratoires publics ou privés. 


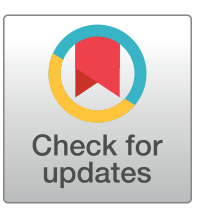

\section{OPEn ACCESS}

Citation: Hansen TVA, Cirera S, Neveu C, Courtot E, Charvet CL, Calloe K, et al. (2021) The narrowspectrum anthelmintic oxantel is a potent agonist of a novel acetylcholine receptor subtype in whipworms. PLoS Pathog 17(2): e1008982. https://doi.org/10.1371/journal.ppat.1008982

Editor: Timothy G. Geary, McGill University, CANADA

Received: September 12, 2020

Accepted: January 13, 2021

Published: February 5, 2021

Copyright: ๑ 2021 Hansen et al. This is an open access article distributed under the terms of the Creative Commons Attribution License, which permits unrestricted use, distribution, and reproduction in any medium, provided the original author and source are credited.

Data Availability Statement: All relevant data are within the manuscript and its Supporting Information files.

Funding: The study was supported by the Independent Research Fund Denmark (DFF 4184-00210, to TVAH) - https://dff.dk/en/frontpage?set_language=en; the Danish National Advanced Technology Foundation /Højteknologifonden/ (5184-00048B, to DAK) https://sciencebusiness.net/categories/danishnational-advanced-technology-foundation; and the
RESEARCH ARTICLE

\section{The narrow-spectrum anthelmintic oxantel is a potent agonist of a novel acetylcholine receptor subtype in whipworms}

\author{
Tina V. A. Hansen $\circledast^{1,2 *}$, Susanna Cirera $\oplus^{1}$, Cédric $\mathrm{Neveu}^{2}$, Elise Courtot ${ }^{2}$, Claude \\ L. Charvet $\oplus^{2}$, Kirstine Calloe $\oplus^{1}$, Dan A. Klaerke ${ }^{1 *}$, Richard J. Martin ${ }^{3}$ \\ 1 Department of Veterinary and Animal Sciences, Faculty of Health and Medical Sciences, University of \\ Copenhagen, Frederiksberg C, Denmark, 2 INRAE, Université de Tours, ISP, Nouzilly, France, \\ 3 Department of Biomedical Sciences, College of Veterinary Medicine, lowa State University, Ames, lowa, \\ United States of America \\ *alstrup@sund.ku.dk (TVAH); dk@sund.ku.dk (DAK)
}

\section{Abstract}

In the absence of efficient alternative strategies, the control of parasitic nematodes, impacting human and animal health, mainly relies on the use of broad-spectrum anthelmintic compounds. Unfortunately, most of these drugs have a limited single-dose efficacy against infections caused by the whipworm, Trichuris. These infections are of both human and veterinary importance. However, in contrast to a wide range of parasitic nematode species, the narrow-spectrum anthelmintic oxantel has a high efficacy on Trichuris spp. Despite this knowledge, the molecular target(s) of oxantel within Trichuris is still unknown. In the distantly related pig roundworm, Ascaris suum, oxantel has a small, but significant effect on the recombinant homomeric Nicotine-sensitive ionotropic acetylcholine receptor ( $N$-AChR) made up of five ACR-16 subunits. Therefore, we hypothesized that in whipworms, a putative homolog of an ACR-16 subunit, can form a functional oxantel-sensitive receptor. Using the pig whipworm $T$. suis as a model, we identified and cloned a novel ACR-16-like subunit and successfully expressed the corresponding homomeric channel in Xenopus laevis oocytes. Electrophysiological experiments revealed this receptor to have distinctive pharmacological properties with oxantel acting as a full agonist, hence we refer to the receptor as an $\mathrm{O}-\mathrm{AChR}$ subtype. Pyrantel activated this novel $O-A C h R$ subtype moderately, whereas classic nicotinic agonists surprisingly resulted in only minor responses. We observed that the expression of the ACR-16-like subunit in the free-living nematode Caenorhabditis elegans conferred an increased sensitivity to oxantel of recombinant worms. We demonstrated that the novel Tsu-ACR-16-like receptor is indeed a target for oxantel, although other receptors may be involved. These finding brings new insight into the understanding of the high sensitivity of whipworms to oxantel, and highlights the importance of the discovery of additional distinct receptor subunit types within Trichuris that can be used as screening tools to evaluate the effect of new synthetic or natural anthelmintic compounds. 
Lundbeck Foundation (R9-A1131, to DAK) https://www.lundbeckfonden.com/en/; RJM is supported by NIH, the National Institute of Allergy and Infectious Diseases grants R01Al047194-17, R21Al092185-01A1 - https://www.nih.gov/aboutnih/what-we-do/nih-almanac/national-instituteallergy-infectious-diseases-niaid The funders had no role in study design, data collection and analysis, decision to publish, or preparation of the manuscript.

Competing interests: The authors have declared that no competing interests exist.

\section{Author summary}

The human whipworm, Trichuris trichiura, is an intestinal parasitic nematode infecting approximately 289.6 million people globally, primarily children living in developing countries. Chronic T. trichiura infection may cause dysentery, growth stunting and decreased cognitive performance. Whipworm infections are notoriously difficult to control with most available anthelmintics, including those commonly used in mass drug administration programs. Recent randomised controlled trials with whipworm-infected humans, have reported superior efficacies of oxantel, a classic, narrow-spectrum anthelmintic, developed for the treatment of Trichuris infections. Despite this knowledge, the molecular target(s) of oxantel within the whipworm has not been identified. In this study, we used the whipworm from pigs as a model and identified a receptor, which was explored using the Xenopus oocyte expression system. We demonstrated that this receptor is highly responsive to oxantel, and therefore a major target of oxantel within Trichuris. In addition, we discovered that this receptor-type is distinctive and only present in the ancient group of parasitic nematodes, Clade I, which also includes the important zoonotic parasite Trichinella. Our findings, explain the specific mode of action of oxantel and open the way for additional characterization of similar receptor subtypes in other medically or veterinary important parasitic nematodes of Clade I.

\section{Introduction}

The human whipworm, Trichuris trichiura, is a Clade I parasitic nematode [1] and one of the Soil Transmitted Helminths (STHs) that is estimated to infect 289.6 million people globally, primarily those living in the tropics and subtropics [2]. Trichuriasis is rarely fatal, but chronically affects the health and nutritional status of the host $[3,4]$, and is known to be notoriously difficult to treat using current anthelmintic drugs (e.g. albendazole and mebendazole) [5-12]. The extensive use of anthelmintics in livestock has led to widespread anthelmintic resistance (AR) to all the major drug classes [13]. Therefore AR in human parasitic nematodes is a concern where decreased susceptibility to albendazole has already been reported for both $T$. trichiura [14] and the human roundworm, Ascaris lumbricoides [15].

Oxantel, is a cholinergic agonist [16], and a $m$-oxyphenol analogue of pyrantel which was developed in 1972 [17] and marketed as a veterinary anthelmintic in 1974 for the treatment of Trichuris [18]. Early clinical trials reported oxantel to be effective against T. trichiura infections $[19,20]$ and recent studies show that oxantel is superior to single-dose albendazole and mebendazole $[21,22]$, which are currently recommended by the WHO for the control of STHs [23]. Cholinergic agonists [16] exert their effect by paralyzing the worms, which are subsequently killed or expelled from the host [24]. This effect is mediated by nicotinic acetylcholine receptors (nAChRs) [24] that are either heteromeric or homomeric five-subunit ligand-gated ion channels expressed in neuronal, muscle and non-neuronal cell membranes [25, 26]. nAChRs of parasitic nematodes have been separated into different pharmacological subtypes based on their sensitivities to a range of cholinergic anthelmintics. Patch-clamp recordings of muscle cells isolated from the pig roundworm A. suum, have revealed that their muscle nAChRs are preferentially activated either by levamisole (L), nicotine (N) or bephenium (B), and correspondingly are described as $L-, N$-, and $B$ - AChRs subtypes [27]. Oxantel is classified as an agonist which is selective for the $\mathrm{N}$-AChR subtypes [16]. The $\mathrm{N}$-AChR subtypes from the model nematode Caenorhabditis elegans and the distantly related pig parasite A. suum are 
homomeric receptors made of the ACR-16 subunits [28, 29]. Both of these ACR-16 receptors have a low, but significant sensitivity to oxantel $[29,30]$.

The high sensitivity of Trichuris spp. to oxantel has previously been speculated to be due to an nAChR subtype present in Trichuris spp. that differs from nAChRs present in other intestinal parasitic nematodes [16]; we hypothesized that a potential homolog of ACR-16 in Trichuris could be a target of oxantel within this species.

Here we describe the functional characterization of a novel AChR subtype from the pig whipworm T. suis with a high sensitivity to oxantel and distinctive pharmacological properties. This homomeric receptor, referred to as an $\mathrm{O}$-AChR subtype, is made of a divergent subunit specific to Clade I nematode species that is only distantly related to ACR-16 from nematode species belonging to other clades. Our results provide new insights about the mode of action of oxantel, its high efficacy on whipworms, and the divergent anthelmintic sensitivity of whipworms.

\section{Results}

\section{Identification of $T$. suis sequences related to the ACR-16 group}

Using the C. elegans ACR-16 deduced amino-acid sequences as a query, tBLASTn search against T. suis, T. muris and T. trichiura genomic data available in WormBase-ParaSite (version WBPS14; http://parasite.wormbase.org/) allowed the identification of two distinct hits for each species sharing identities ranging from $46 \%$ to $47 \%$ with the C. elegans sequence. Subsequently, a second tBLASTn search against nematodes genomic data available at the NCBI was performed with the retrieved Trichuris spp. sequences. Homologies could be identified with either of the acr-16 or acr-19 genes from nematode species representative from the nematoda phylum. Using a panel of representative C. elegans nAChRs subunits as references, a phylogenetic analysis including the Trichuris spp. and their putative homologs in the closely related species Trichinella spiralis was carried out (Fig 1). Trichuris spp. sequences were found to form two distinct clusters. The first one presented a clear orthologous relationship with ACR-19, the second one clustered apart from the other subunits and belonged to the ACR-16 group [31]. An additional analysis, including other related sequences from nematode species representative from the different clades of the nematoda phylum (S1 Fig) further confirmed that Clade I nematode species (including Trichuris spp.) possess a divergent group of AChR subunit related to the ACR-16 subunit. Consequently, the corresponding sequences from Clade I nematode species were named ACR-16-like.

\section{Molecular cloning of the Tsu-acr-16-like coding sequence}

In the present study, based on the current knowledge of the original mode of action of oxantel $[16,29]$, we hypothesized that the divergent ACR-16-like from Trichuris spp. could represent a preferential target for this narrow-spectrum anthelmintic. Using T. suis as a model, we cloned its acr-16-like full-length cDNA sequence as a matter of priority and deposited the sequence in GenBank under the accession number MT386096. During PCR amplification for the cloning, we observed several band sizes and tried unsuccessfully to clone all of them. Therefore, it is possibly that there are at least 2 other isoforms of the Tsu-ACR-16-like subunits. An alignment of the Tsu-ACR-16-like sequence with its closely related counterparts from T. muris, T. trichiura, T. spiralis and C. elegans is provided in Fig 2. The Tsu-ACR-16-like subunit was found to share typical features of $\mathrm{nAChR}$ subunits including a predicted signal peptide, a Cys-loop motif, four transmembrane regions (TM1-TM4), and the YxCC motif which characterize an $\alpha$-type nAChR receptor subunit. 


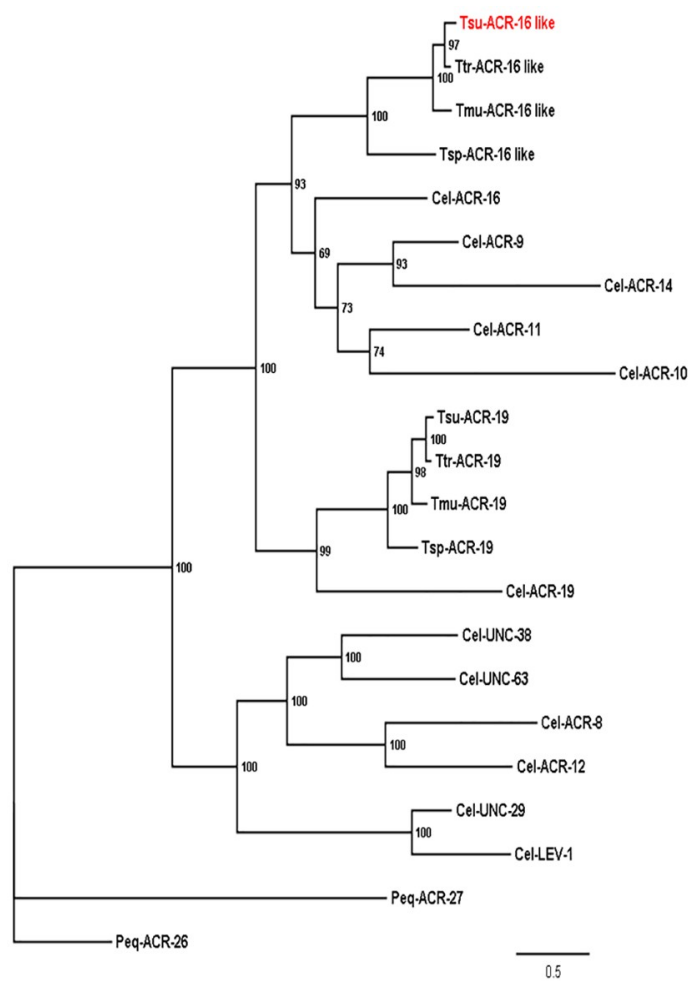

ACR-16 GROUP

UNC-38 GROUP

ACR-8 GROUP

UNC-29 GROUP

Fig 1. Maximum likelihood tree showing relationships of the ACR-16 related acetylcholine receptor (nAChR) subunits from Trichuris spp., with other C. elegans and T. spiralis $\mathrm{nAChR}$ subunits. The tree was built upon an alignment of nAChR subunit deduced amino-acid sequences. The tree was rooted with the Parascaris equorum ACR26 and ACR-27 sequences that are absent from C. elegans and clade I nematode species [34]. Scale bar represents the number of substitutions per site. Bootstrap values are indicated on branches. Accession numbers for sequences used in the phylogenetic analysis are provided in the Material and Methods section. C. elegans nAChR subunit groups are named as proposed by Mongan et al. [31], Cel, Tsu, Ttr, Tmu, Tsp and Peq refer to Caenorhabditis elegans, Trichuris suis, Trichuris trichiura, Trichuris muris and Parascaris equorum, respectively.

https://doi.org/10.1371/journal.ppat.1008982.g001

\section{Tsu-ACR-16-like subunits form a functional homomeric receptor when co- expressed with the ancillary protein RIC-3 in Xenopus laevis oocytes}

Previous studies have shown that Cel-ACR-16 and Asu-ACR-16 can form functional homomeric receptors when expressed in X. laevis oocytes with the ancillary protein RIC-3 [29, 32]. Thus, we explored the requirement of RIC-3, and compared Tsu-ACR-16-like subunit expression using either the RIC-3 from Xenopus laevis (Xla-RIC-3), or RIC-3 from various nematode species to reconstitute a functional AChR in X. laevis oocytes. Xenopus laevis oocytes were micro injected with Tsu-acr-16-like cRNA in combination with Xla-ric-3, Asu-ric-3, Haemonchus contortus ric-3 isoform 1 (Hco-ric-3.1), or Caenorhabditis elegans ric-3 (Cel-ric-3). Tsu-acr-16-like cRNA or Asu-ric-3 cRNA alone as well as non-injected oocytes were used as controls.

The combination of Tsu-acr-16-like with any of the ric-3 cRNAs led to robust expression of functional receptors responding to $100 \mu \mathrm{M}$ acetylcholine (ACh), which elicited inward currents in the $\mu \mathrm{A}$ range (Fig 3 ). The largest relative currents were measured in oocytes coinjected with Tsu-acr-16-like and Asu-ric-3 cRNA, however, no statistically significant differences $(P>0.9)$ were found between the effect of RIC-3 from $X$. laevis and nematodes of Clade III (A. suum) and Clade V (C. elegans and H. contortus). Non-injected oocytes, or oocytes 


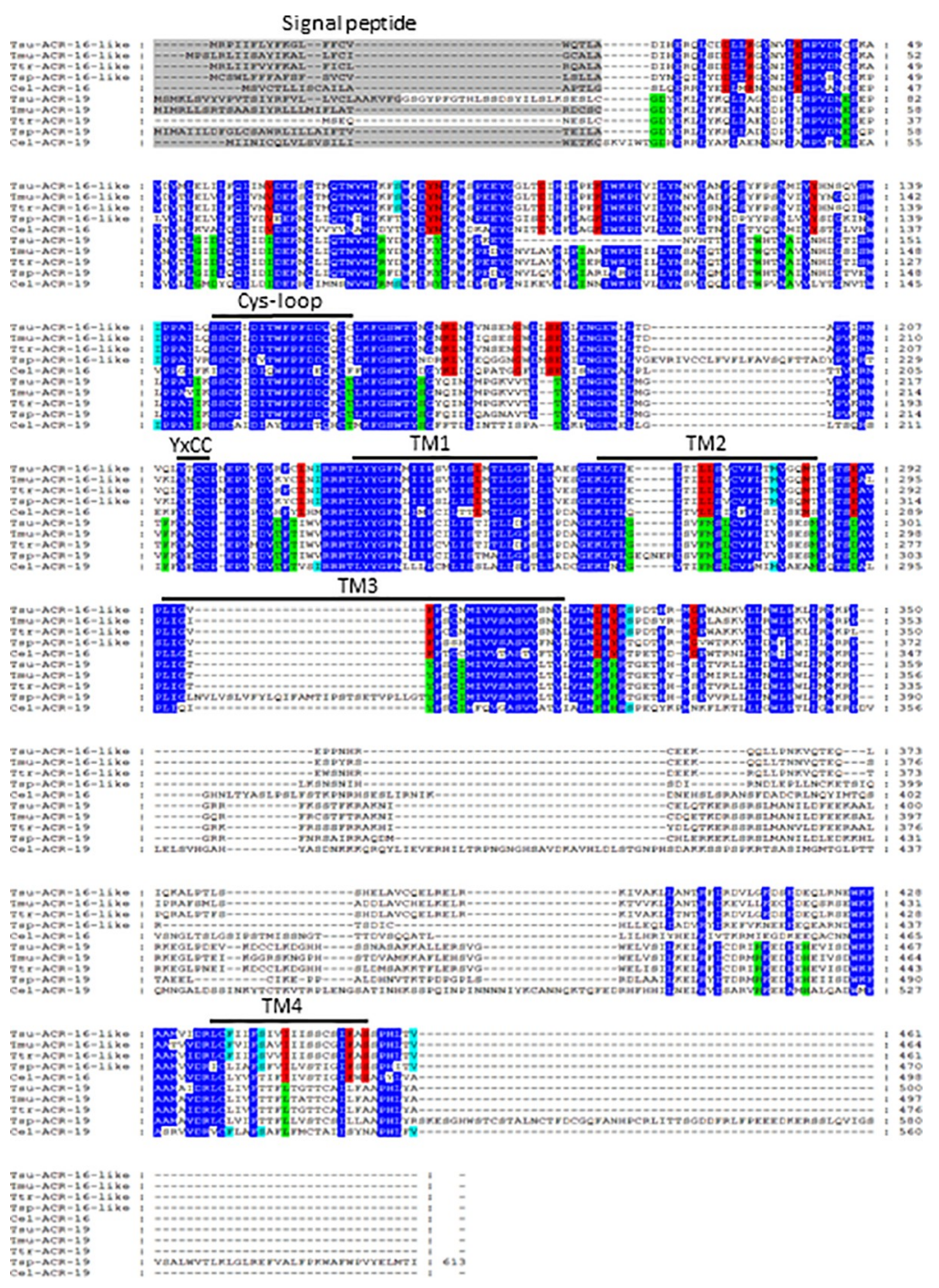

Fig 2. Amino acid alignment of ACR-16-(like) and ACR-19 subunit sequences from the Clade I parasitic nematodes Trichuris suis, T. trichiura, T. muris, Trichinella spiralis and Caenorhabditis elegans. Predicted signal peptide sequences are shaded in grey, the Cys-loop, the transmembrane regions (TM1-TM4), and the YxCC motif that characterize an $\alpha$-subunit are indicated above the sequences. Conserved amino acids between ACR-16-(like) and ACR-19 sequences (dark blue), conserved amino acids between all ACR-16-(like) sequences (red), conserved amino acid between all ACR-19 sequences (light green), conserved amino acid between ACR-16-like sequences of Clade I parasitic nematodes and ACR-19 of C. elegans (light blue).

https://doi.org/10.1371/journal.ppat.1008982.g002

injected with either Tsu-acr-16-like or Asu-ric-3 cRNA alone, did not respond to $100 \mu \mathrm{M} \mathrm{ACh}$, highlighting the need of RIC-3 for the functional expression of the homomeric Tsu-ACR16-like receptor. Representative traces of the inward currents for each injection type, and a bar chart presenting their mean \pm SEM normalized values are shown in Fig 3. In addition, the results showed no significant difference between the reversal potentials observed in $1 \mathrm{mM}(9.7$ +/- $4.3 \mathrm{mV})$ and $10 \mathrm{mM}(10.2+/-3.4 \mathrm{mV})$ external $\mathrm{Ca}^{2+}$ suggesting a low $\mathrm{Ca}^{2+}$ permeability for the receptor Based on these results, all subsequent recordings were performed on oocytes co-injected with Tsu-acr-16-like and Asu-ric-3 cRNAs. 

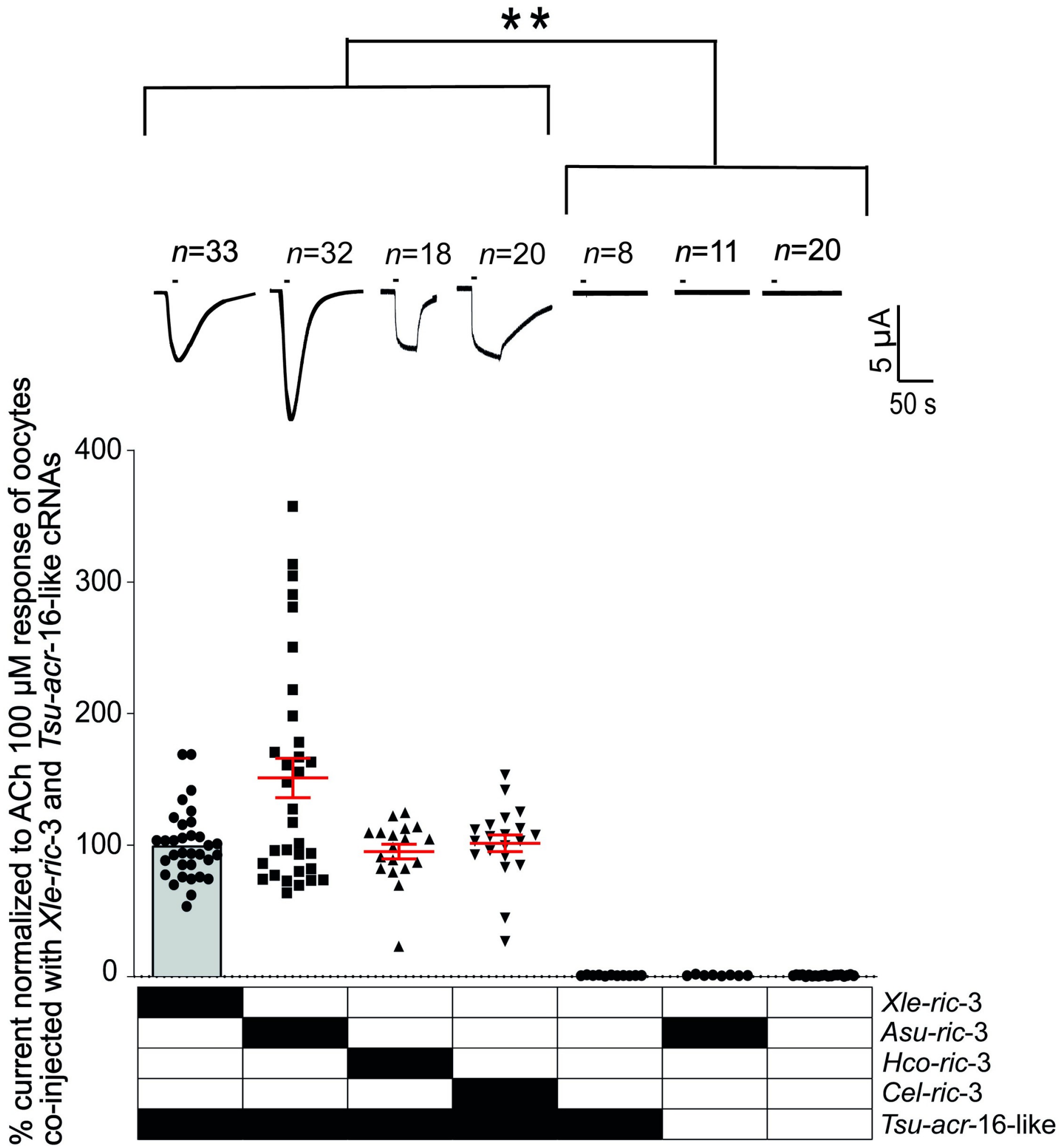

Fig 3. Effect of the ancillary protein Resistance-to-cholinesterase (RIC-3) from Xenopus laevis (Xla-RIC-3), Ascaris suum (Asu-RIC-3), Haemonchus contortus isoform 1 (Hco-RIC-3.1), Caenorhabditis elegans (Cel-RIC-3) on the functional expression of the ACR-16-like nAChR from Trichuris suis (Tsu-ACR-16-like receptor). Representative sample traces of inward current in response to $100 \mu \mathrm{M}$ ACh are shown together with a scatter dot plot presenting the relative currents

$($ mean \pm SEM). Non-injected oocytes and oocytes injected with Tsu-acr-16-like- or Asu-ric-3 cRNA alone did not respond to $100 \mu \mathrm{M}$ ACh which was significantly different 
from oocytes co-injected with Tsu-acr-16-like and either of the tested ric-3 cRNAs $\left({ }^{* *} P<0.01\right)$. The relative currents of oocytes co-injected with Tsu-acr-16-like and either of the tested ric-3 cRNAs were not significantly different $(P>0.9)$ as indicated, Kruskal-Walis Test.

https://doi.org/10.1371/journal.ppat.1008982.g003

\section{Oxantel is a potent agonist on the Tsu-ACR-16-like receptor}

To explore the effect of oxantel and perform a detailed pharmacological characterization of the Tsu-ACR-16-like receptor, we used 4 cholinergic anthelmintics (i.e. oxantel, pyrantel, morantel and levamisole) and $5 \mathrm{nAChR}$ agonists (i.e. epibatidine, nicotine, 3-bromocytisine, DMPP and cytisine). Fig 4 shows the rank order potency series of these drugs, representative traces of the inward currents induced by each of them, the number of oocytes $(n)$ used for each agonist, along with a bar chart presenting the normalized mean \pm SEM for each drug group. Oxantel was the most potent test agonist on the Tsu-ACR-16-like receptor and induced a current

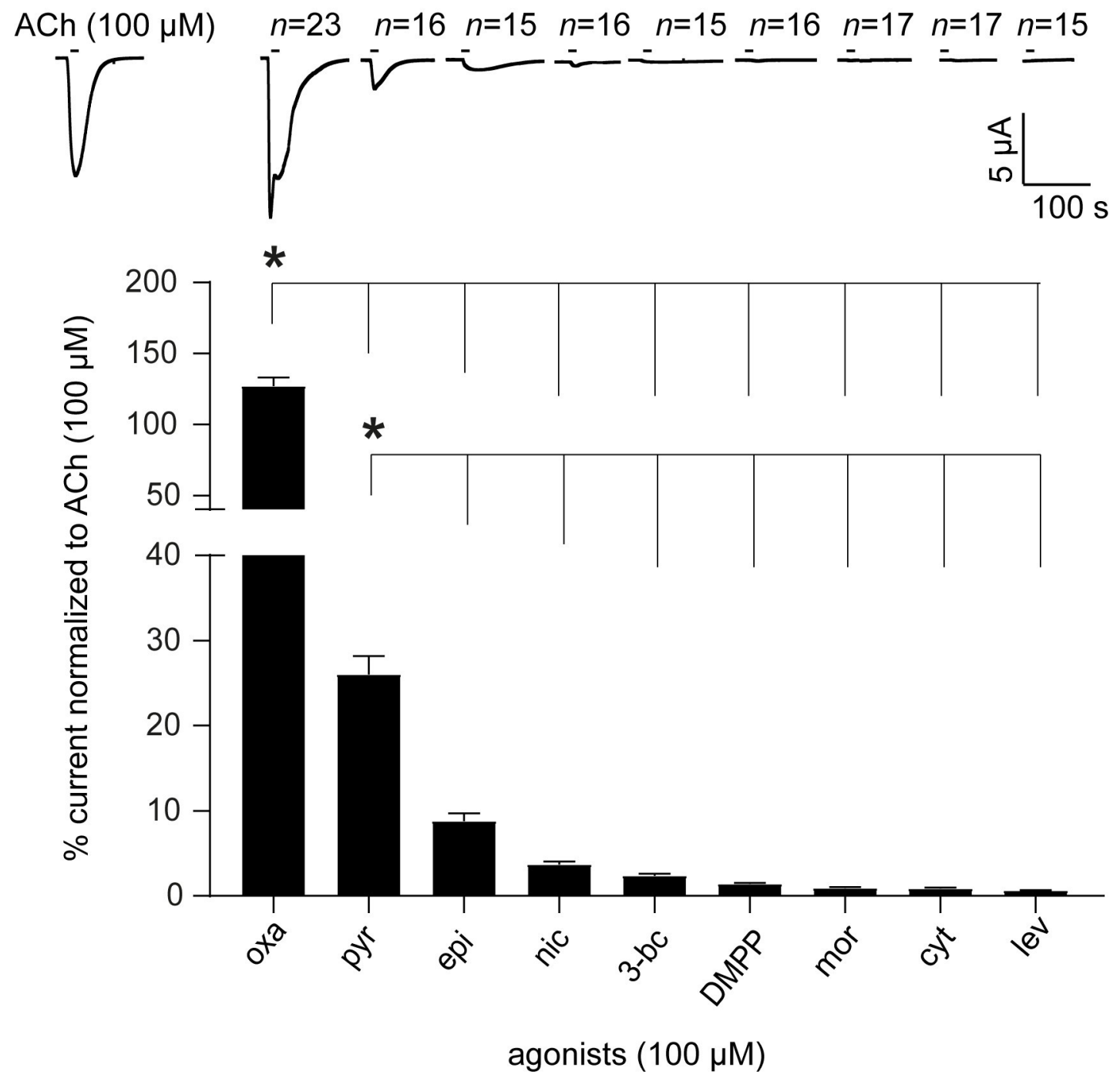

Fig 4. The effect of 9 agonists on $T s u$-ACR-16-like receptor. Representative sample traces and a bar chart (mean \pm SEM) show the rank order potency series of 4 cholinergic anthelmintics: oxantel (oxa), pyrantel (pyr), morantel (mor), levamisole (lev) and 5 nAChR agonists: epibatidine (epi), nicotine (nic), 3-bromocytisine (3-bc), dimethylphenylpiperazinium (DMPP) and cytisine (cyt). $P<0.05$; significantly different as indicated; Turkey's multiple comparison test.

https://doi.org/10.1371/journal.ppat.1008982.g004 
response in the same range as the control response of $100 \mu \mathrm{M}$ ACh. Pyrantel also induced a relatively high current response, however; the nicotinic agonists: epibatidine, nicotine, 3-bromocytisine, DMPP and cytisine as well as the cholinergic anthelmintics, morantel and levamisole, were the least potent. The rank order potency series for the agonist drugs on the Tsu-ACR16-like receptor when normalized to control oocytes exposed to $100 \mu \mathrm{M}$ ACh was: oxantel ACh $>>>$ pyrantel $>>>$ epibatidine $>$ nicotine $\sim$ 3-bromocytisine $\sim$ DMPP $\sim$ morantel $\sim$ cytisine $\sim$ levamisole. Taken together, these observations provide strong evidence that the TsuACR-16-like receptor represents the preferential molecular target for oxantel. Interestingly, when exposed to $100 \mu \mathrm{M}$ ACh for 1-3 min the Tsu-ACR-16-like receptor did not show fastdesensitization kinetics (S2 Fig) which is a distinctive characteristic of the $\mathrm{N}$-AChR of nematode such as Asu-ACR-16 [29] and the ACR-16 from Parascaris equorum (Peq-ACR-16) [33].

\section{Dose-response curve of oxantel and pyrantel}

Oxantel and pyrantel have similar chemical structures (Fig 5A), but their potencies on the TsuACR-16-like receptor were found to be significantly different (Fig 4). We performed a doseresponse study on oxantel, pyrantel and $\mathrm{ACh}$ to determine their $E C_{50}$ values, their relative maximum current responses, $I_{\max }$, and their Hill slopes, $n_{\mathrm{H}}$. The mean current response of positive control oocytes exposed to $300 \mu \mathrm{M}$ ACh was used for normalization. Fig 5B shows representative traces and dose-response relationships of the normalized inward currents (mean \pm SEM) induced by different concentrations of oxantel, pyrantel and ACh. The resulting $E C_{50} \pm$ SE for oxantel $(9.49 \pm 1.13 \mu \mathrm{M})$ was much lower than that of pyrantel $(148.5 \pm 1.19 \mu \mathrm{M}, P<0.001)$ and slightly lower than that of ACh $(14.5 \pm 1.03)$. The relative maximum current response, $I_{\max }$ (mean $\pm \mathrm{SE}$ ) was significantly larger for oxantel $(86.85 \pm 4.63 \%)$ than pyrantel $(29.41 \pm 1.95 \%, P=0.003)$, whereas no significant difference was found between the Hill slopes, $n_{\mathrm{H}}$ (mean $\pm \mathrm{SE}$ ), of oxantel $(2.51 \pm 1.31$ ), pyrantel $(3.13 \pm 1.07)$ and $\mathrm{ACh}(2.14 \pm 0.1)$.

\section{Antagonists}

To further characterize the pharmacology of Tsu-ACR-16-like receptor, we tested 3 selected antagonists: dihydro- $\beta$-erythroidine (DH $\beta E), \alpha$-bungarotoxin $(\alpha-\mathrm{BTX})$ and the anthelmintic, derquantel. Fig 6 shows the effect of $10 \mu \mathrm{M}$ DHBE and $10 \mu \mathrm{M}$ derquantel on the Tsu-ACR16-like receptor along with representative current responses. The initial $\mathrm{ACh}(100 \mu \mathrm{M})$ current response of each oocyte was used for normalization, to measure the reduced current responses in the presence of the antagonists. For DHßE, the mean \pm SEM inhibition was very small (i.e. $7.60 \pm 1.6 \%)$ and no inhibition was observed for derquantel $(0.16 \pm 1.6 \%)$. The effect of $\alpha$-BTX is given in Fig 7A which shows the response-inhibition of the Tsu-ACR-16-like receptor to $100 \mu \mathrm{M}$ ACh when $10 \mu \mathrm{M} \alpha$-BTX is applied $10 \mathrm{~s}$ before the second application of $100 \mu \mathrm{M}$ ACh (test oocytes). Fig 7B shows the effect of the Tsu-ACR-16-like receptor when exposed to repetitive applications of $100 \mu \mathrm{M} \mathrm{ACh}$, only (control oocytes). The first current response of $100 \mu \mathrm{M}$ ACh (ACh1) was used for normalization. Representative current traces along with a bar chart presenting the normalized mean \pm SEM of the second and third drug application of Tsu-ACR16-like receptor expressing- and un-injected control oocytes are given in Fig 7A and 7B. The $10 \mu \mathrm{M} \alpha$-BTX significantly $(P<0.0001)$ reduced the current response of ACh to $8.3 \pm 2.4 \%$ of the Tsu-ACR-16-like receptor expressing oocytes (Fig 7A). This reduction was not observed in the control oocytes (Fig 7B), thus, when $\alpha$-BTX was applied $10 \mathrm{~s}$ before the second application of $\mathrm{ACh}$, the current response was significantly reduced in test oocytes as compared to control oocytes (Fig $7 \mathrm{~A}$ and $7 \mathrm{~B}, P<0.0001$ ). 
A<smiles>CN1CCCN=C1/C=C/c1cccc(O)c1</smiles><smiles>CN1CCCN=C1/C=C/c1cccs1</smiles>

B $\quad$ ACh $(300 \mu \mathrm{M})$
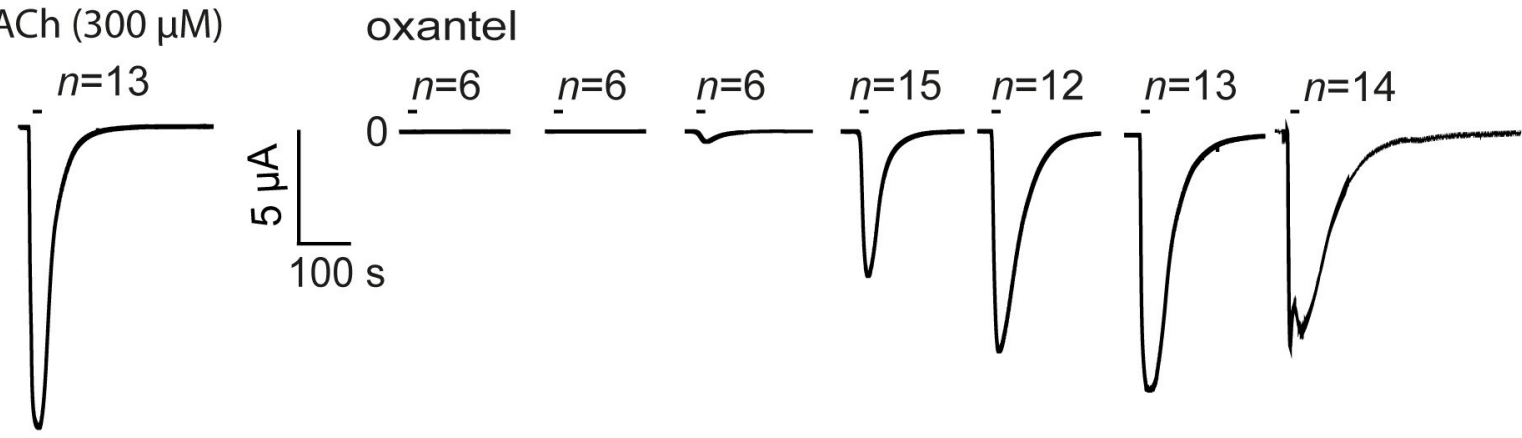

ACh $(300 \mu \mathrm{M})$

pyrantel

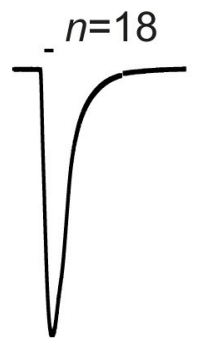

$\left.0 \stackrel{n=6}{=} \stackrel{n=6}{-} \stackrel{n=6}{=} \stackrel{n=6}{=} \stackrel{n=15}{\sim}]^{-n} \sqrt[n=23]{n}\right]^{-i}$

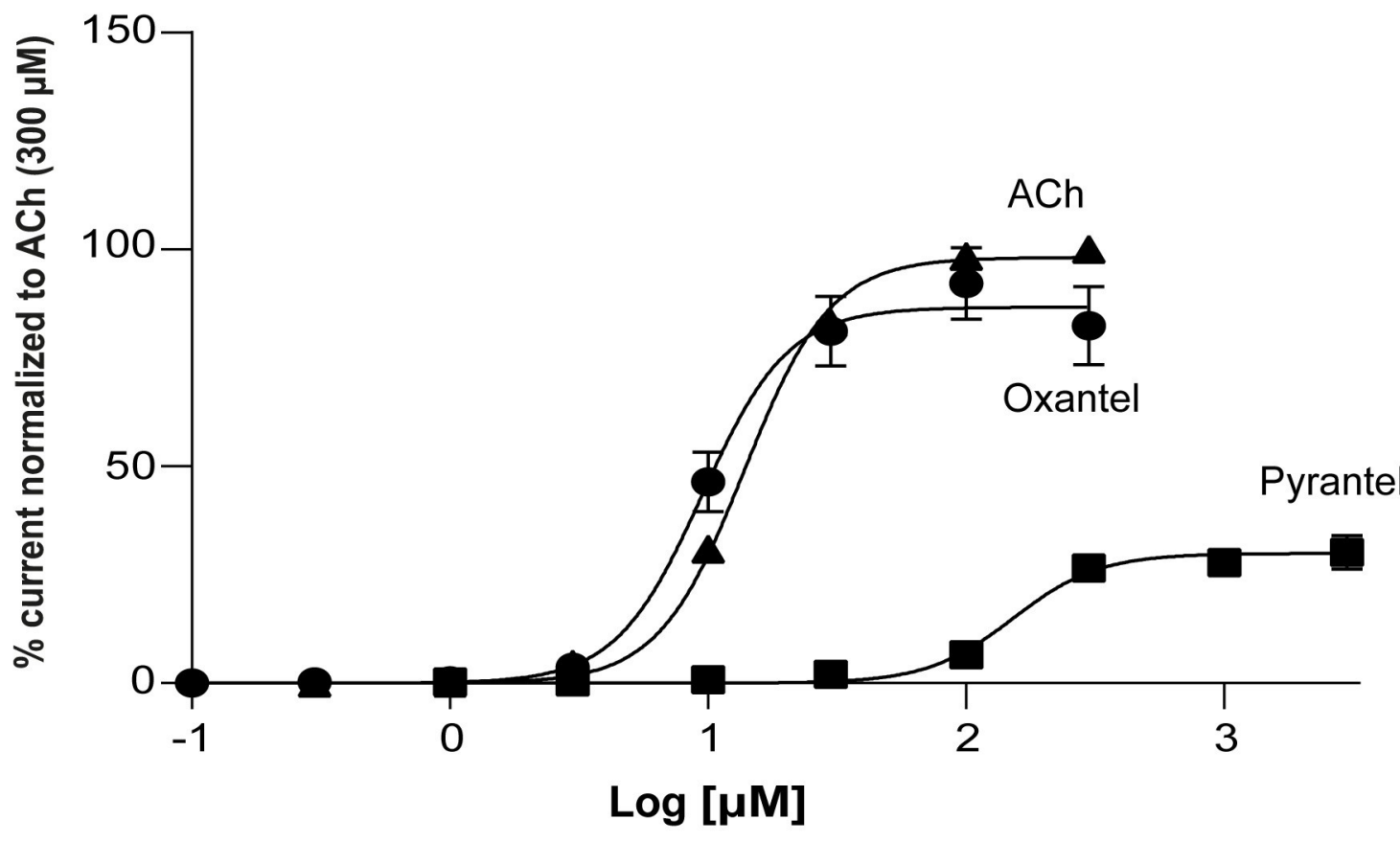


Fig 5. A: Chemical structure of oxantel and pyrantel. Oxantel: free drawing after https://pubchem.ncbi.nlm.nih.gov/compound/oxantel\#section=2D-Structure. Pyrantel: free drawing after https://pubchem.ncbi.nlm.nih.gov/compound/pyrantel\#section=2D-Structure B: Dose-response curves for oxantel (oxa), pyrantel (pyr) and acetylcholine (ACh). The current response on Tsu-ACR-16-like receptor is normalised to current responses induced by $300 \mu \mathrm{M}$ ACh and given as mean \pm SEM. The $\mathrm{EC}_{50} \pm$ SD values were $9.48 \pm 1.15 \mu \mathrm{M}$ for oxa, $152.7 \pm 1.20 \mu \mathrm{M}$ for pyr and $14.5 \pm 1.03$ for $\mathrm{ACh}$, the relative maximum current responses, $I_{\max }$ were $86.85 \pm 4.63 \%$ and $29.41 \pm 1.95 \%$, and the Hill slope, $n_{\mathrm{H}}, 2.51 \pm 1.30,3.13 \pm 1.07$ and $2.14 \pm 0.1$ for oxa, pyr and ACh respectively.

https://doi.org/10.1371/journal.ppat.1008982.g005

\section{The expression of the Tsu-ACR-16-like subunit in Caenorhabditis elegans increases the sensitivity to oxantel}

The heterologous expression of parasitic nematode genes in C. elegans has successfully been used to decipher the drug sensitivity of parasitic nAChR-subunits [34-36]. To investigate the oxantel sensitivity of the $T s u$-ACR-16-like receptor, we generated three recombinant C. elegans lines expressing the Tsu-ACR-16 like receptor under the control of the C. elegans myo3 body wall muscular promotor. Wildtype (wt) C. elegans (named N2) have previously been described to be relative unaffected by oxantel at a concentration of $1 \mathrm{mM}$ [37], thus, ideally suited to investigate the oxantel sensitivity of the recombinant worms.

The effect of $500 \mu \mathrm{M}$ oxantel on wt N2 and recombinant worms for $24 \mathrm{~h}$ is shown in Fig 8 and S1 Video. First, we performed a thrashing assay in M9 medium to determine if the overexpression of pmyo3::Tsu-acr-16-like receptor had an impact on the basal motility. We observed no significant difference between each line $(P=0.25)$. Second, to investigate the oxantel

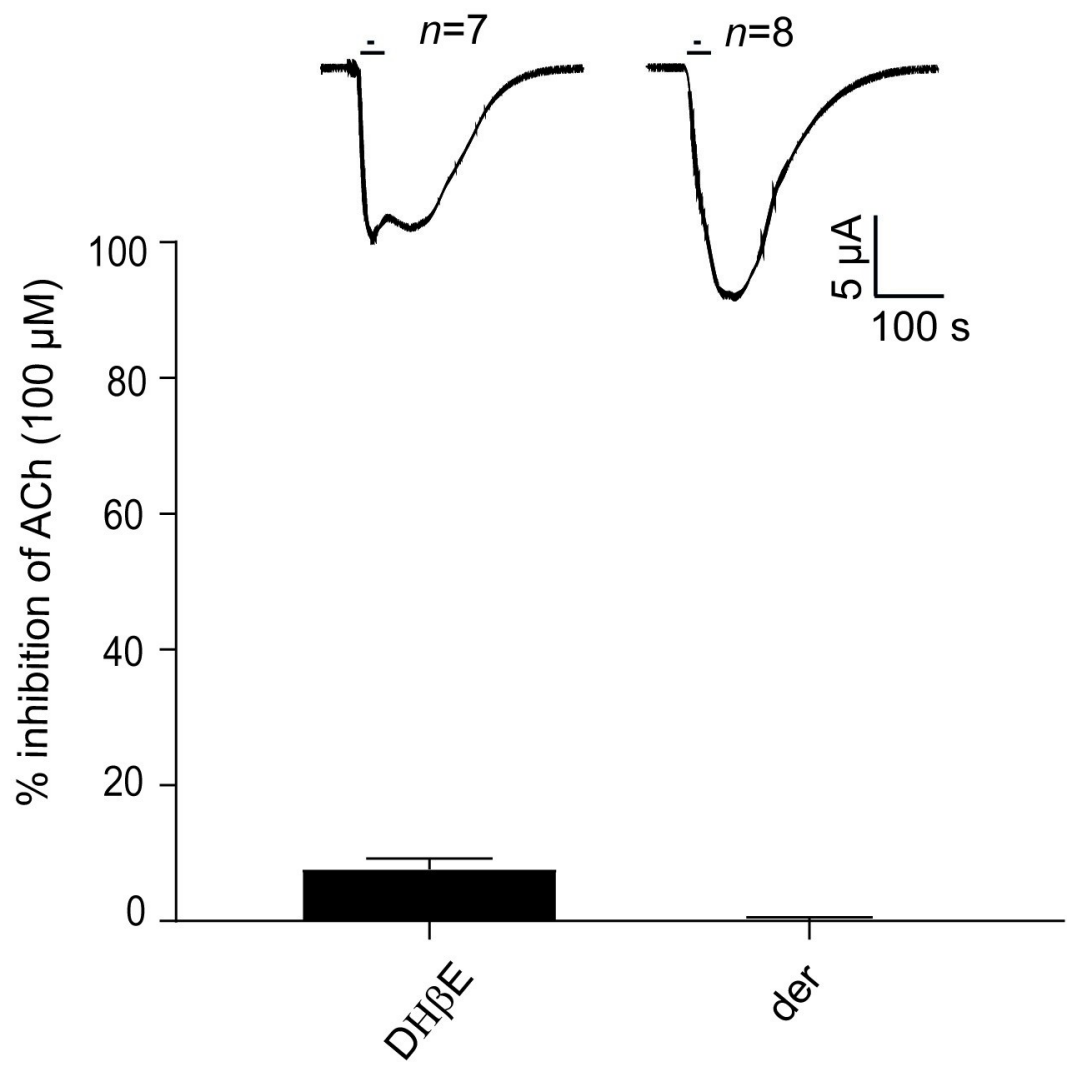

Fig 6. Effect of the antagonists: dihydro- $\beta$-erythroidine (DHßE) and derquantel (der) on Tsu-ACR-16-like receptor mediated $100 \mu \mathrm{M} A C h$ current response. Results are given as normalized mean \pm SEM inhibition of the initial current response of $100 \mu \mathrm{M}$ ACh. DH $\beta E$ produced an almost insignificant block of the Tsu-ACR-16-like receptor mediated $\mathrm{ACh}$ response (i.e. $7.60 \pm 1.61 \%)$ and no effect was observed for der $(0.16 \pm 1.61 \%)$.

https://doi.org/10.1371/journal.ppat.1008982.g006 
A
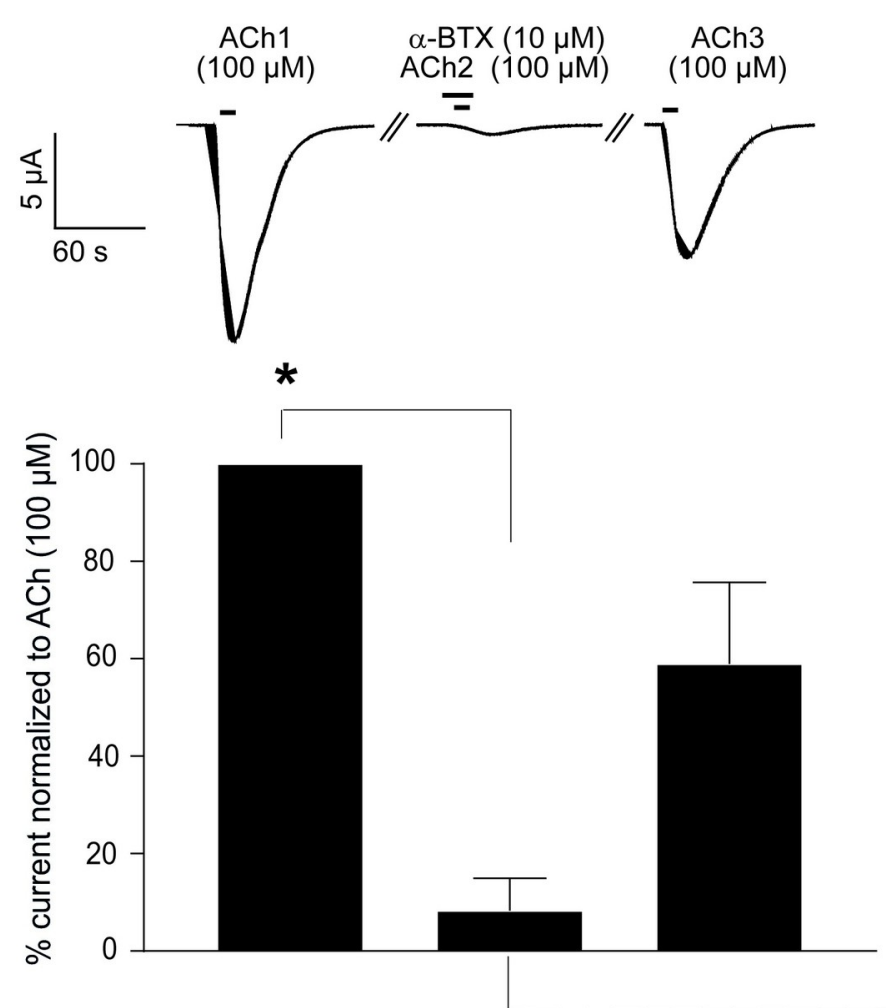

B
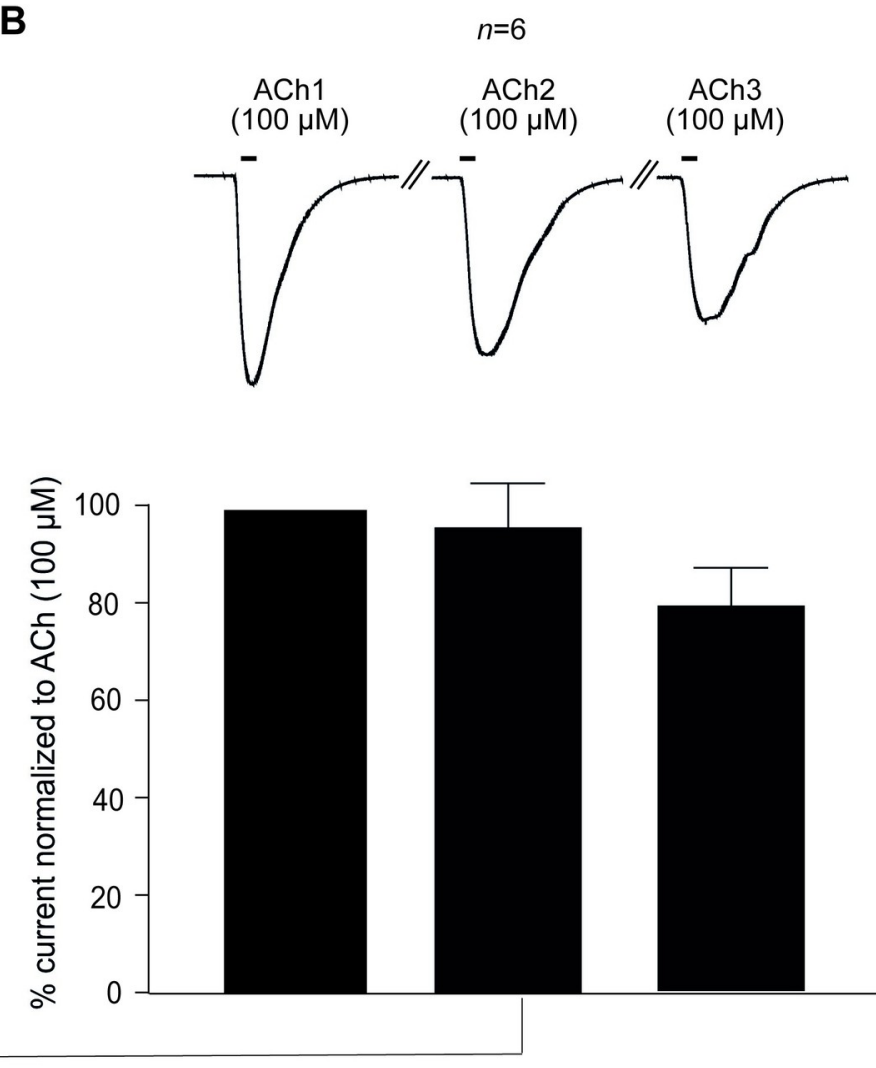

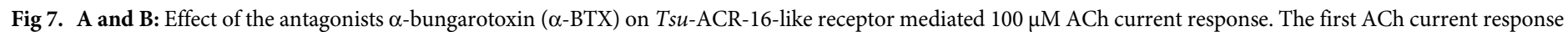

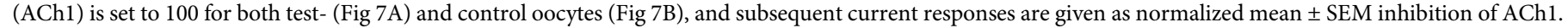
$P<0.05$; significantly different as indicated, Dunnett's test.

sensitivity, we performed a thrashing assay after 24 hours of exposure to $500 \mu \mathrm{M}$ oxantel. Strikingly, we observed a significant difference in the motility between wt N2 and each of the recombinant lines $(P<0.001)$. Indeed, the motility of the recombinant lines was on average inhibited by $80 \%$, whereas the motility of wt $\mathrm{N} 2$ worms was only decreased by $30 \%$. As control, we determined the motility of all lines after 24 hours in M9, only, and no significant difference was noticed between neither of the lines (S3 Fig). These results strongly suggests that the Tsuacr-16-like subunit indeed has the ability to confer oxantel sensitivity to C. elegans, and support that the Tsu-acr-16-like receptor is a major target of oxantel within T. suis. Therefore, the Tsu-ACR-16-like receptor will be henceforth referred to as the Oxantel-sensitive AChR $(O$ $\mathrm{AChR})$.

\section{Discussion}

In the present study, we report the identification and the functional expression of the TsuACR-16-like receptor, a novel AChR subtype corresponding to the first specific drug target for oxantel to be reported in any nematode species. In reference to the previously reported $L$ AChR, $N$-AChR, and $M$-AChR (respectively for Levamisole-sensitive, Nicotine-sensitive and Morantel- sensitive-AChR subtypes), we named the novel oxantel-sensitive AChR subtype: the $O-A C h R$. 


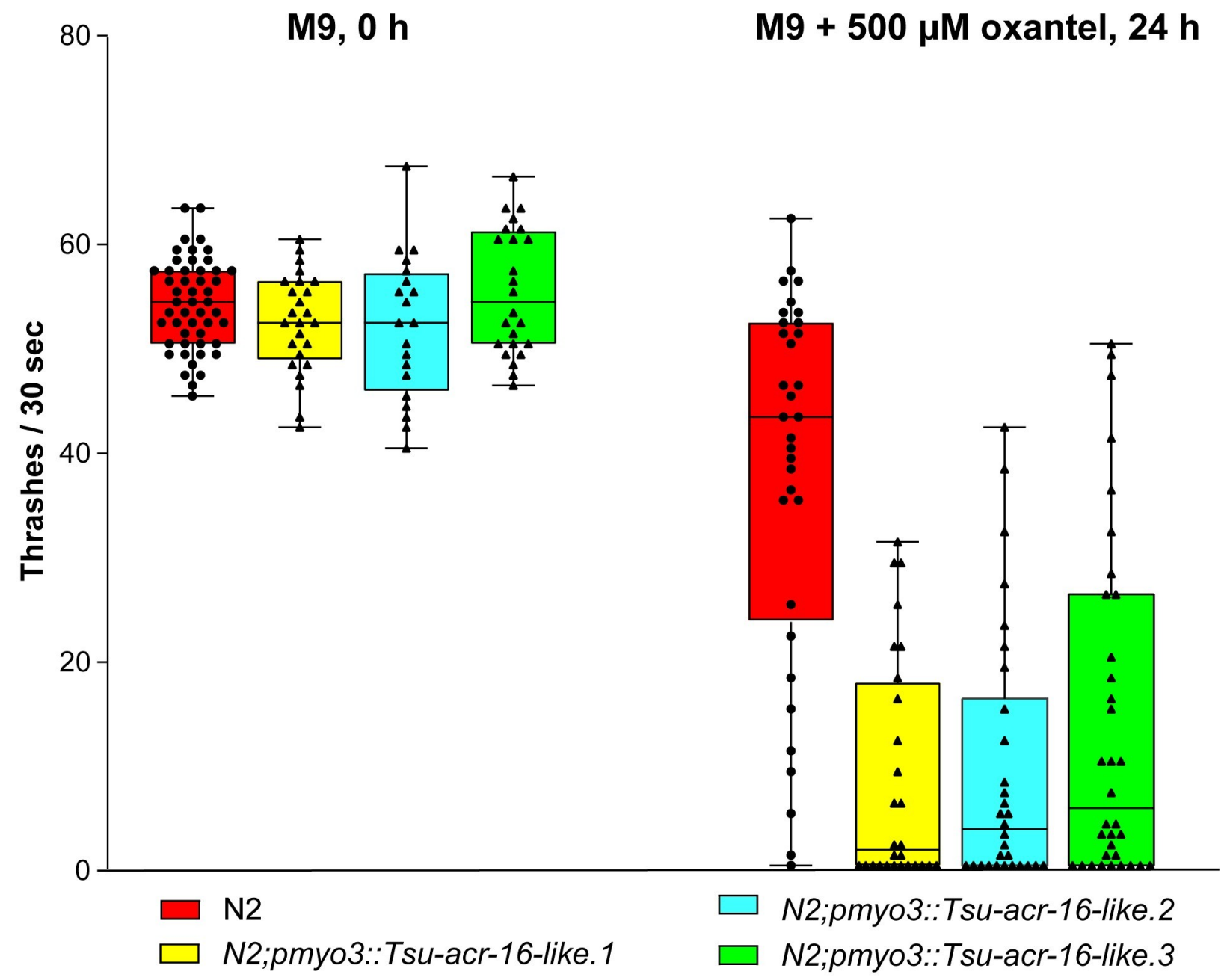

Fig 8. Heterologous expression of Tsu-ACR-16-like receptor in Caenohabditis elegans confer oxantel sensitivity to the recombinant worms Boxplot depicts number of thrashes/30 sec of worms in M9 media prior to incubation $(0 \mathrm{~h})$ and after $24 \mathrm{~h}$ incubation with $(+) 500 \mu \mathrm{M}$ oxantel. The number of thrashes were significantly higher for wildtype C. elegans; $\mathrm{N} 2$ (red, $n=34$ ) than each of the recombinant C. elegans N2; pmyo3::Tsu-acr-16-like lines: line 1 (yellow, $P<0.0001, n=28$ ), line 2 (blue, $P<0.0001, n=30$ ), line 3 (green, $P<10^{-4}, n=34$ ) when incubated in M9 media with $500 \mu \mathrm{M}$ oxantel.

https://doi.org/10.1371/journal.ppat.1008982.g008

\section{The $\mathrm{O}$-AChR is a novel receptor subtype specific to Clade I nematode species with original pharmacological properties}

Use of screens for C. elegans mutants that survive exposure to the broad-spectrum anthelmintics provided a means to decipher their molecular targets in a wide range of nematode species. However, this approach was not helpful for oxantel because the C. elegans is insensitive to this drug [37]. The weak, but measurable activity of oxantel on recombinant $N$-AChR from C. elegans and A. suum, supported the hypothesis that a putative ACR-16 homologs in Trichuris species could be involved in an oxantel-sensitive receptor. Williamson et al. [38] reported that only two members from the ACR-16 group could be identified in the genomic data from the Clade I species T. spiralis. In agreement with this finding, our search for ACR-16 homologs only retrieved two sequences in each of the Trichuris species investigated in the present work. The first one corresponded to the highly conserved AChR subunit encoded by the acr-19 gene; the second one corresponded to a highly divergent subunit specific to Clade I nematode species designated as ACR-16-like. 
When co-expressed in the X. laevis oocytes with the ancillary protein RIC-3, the ACR16-like subunits from $T$. suis formed a functional homomeric channel (O-AChR) with unexpected pharmacological properties. Indeed, this receptor was highly sensitive to oxantel which is in contrast to the Asu-ACR-16 for which a low agonist effect of oxantel has been reported (i.e. $<10 \%$ of the control ACh current) [29] and to the Cel-ACR-16 on which oxantel has an antagonistic effect [30]. Likewise, pyrantel had a relatively high effect on the Tsu-O-AChR, whereas pyrantel had no agonist effect on Asu-ACR-16 [29] or Cel-ACR-16, but in contrast, showed an antagonistic effect on the latter, which was ascribed to pyrantel acting as an open channel blocker [28]. In accordance with this assumption, patch-clamp recording studies from isolated A. suum muscle cells, show that both oxantel and pyrantel act as agonists and open channel blockers $[39,40]$. Another surprising difference between the Tsu-O-AChR and the ACR-16 receptors from A. suum, C. elegans and $P$. equorum is the lack of sensitivity to nicotinic agonists $[28,29,33]$. Since oxantel has been characterized as an agonist selective for the $\mathrm{N}$-subtypes of the ionotropic AChRs [16] which include the ACR-16 receptors, we expected the Tsu-O-AChR receptor to be highly sensitive to nicotine, cytisine, 3-bromocytisine, epibatidine and DMPP, but only small current responses were observed using these agonists. Another feature of the Tsu-O-AChR receptor is its slow desensitization kinetics, which contrasts with the faster desensitization of the N-AChR from C. elegans [41], A. suum [29] and P. equorum [33].

Interestingly, we also showed that the antagonist, $\alpha$-BTX had a potent inhibitory effect on the ACh induced current responses of the Tsu-O-AChR whereas A. suum [29] and C. elegans $N$-AChR [28] are nearly insensitive to $\alpha$-BTX. We point out however, that $\alpha$-BTX only induced a strong inhibitory effect when $\alpha$-BTX was applied $10 \mathrm{~s}$ before the application of ACh suggesting a slow association time of $\alpha-\mathrm{BTX}$. The Tsu-O-AChR was virtually insensitive to $\mathrm{DH} \beta E$ and insensitive to derquantel. This also contrasts with the $\mathrm{Asu}-\mathrm{N}-\mathrm{AChR}$ which is moderately sensitive to DH $\beta E$ ( 65\% inhibition) and derquantel ( 60\% inhibition) [29] and the $\mathrm{Cel}-\mathrm{N}$-AChR which is highly sensitive to DHßE [28].

Taken together, these results strongly support our hypothesis that $\mathrm{O}-\mathrm{AChR}$ and $\mathrm{N}$-AChR represent two distinct classes of ionotropic AChR. Despite the important differences, it is noteworthy that there are also similarities between the $O$ - and $N$-AChR: both subtypes are insensitive towards the anthelmintic drugs levamisole or morantel [27-29].

\section{Sensitivity to oxantel and pyrantel}

Small changes in structure of acetylcholine agonists can have large effects on the selectivity and affinity of nicotinic agonists [42]. Perhaps it is not surprising that pyrantel which was modified by replacing the 2 -thiophene moiety with a $m$-oxyphenol group [17] to produce oxantel has a different pharmacology. Thus, the anthelmintic spectrum of oxantel and pyrantel is very different. Pyrantel is a broad-spectrum anthelmintic with no effect on adult Trichuris [17] whereas oxantel is a narrow-spectrum anthelmintic with a potent and selective effect on adult Trichuris [19-22]. This spectrum difference has previously raised the question whether a cholinergic receptor subtype present in Trichuris spp. are different from other intestinal nematode parasites [16], which indeed is now strongly supported by our results. In addition, it is remarkable that a recent in silico ligand binding analysis of the extracellular domains of ACR-16 from Ancylostoma caninum, Necator americanus, C. elegans and T. muris predicted oxantel to bind to ACR-16 of T. muris (Tmu-ACR-16-like) with high affinity [43]. Presuming that the ACR-16 of T. muris and T.suis have similar pharmacological profiles, our results indeed support these docking simulations.

In our study, we observed that oxantel, but not pyrantel, in some recordings induced a "noisy" channel activation at high concentration (i.e. $300 \mu \mathrm{M}$ ), an initial increase in current on 
washout, and a slightly lower response to $300 \mu \mathrm{M}$ than $100 \mu \mathrm{M}$. These observations suggest oxantel to act as an open channel blocker on the Tsu-ACR-16-like receptor and is in accordance with what previously described for A. suum [39].

\section{The Tsu-acr-16-like receptor confers oxantel sensitivity to Caenorhabditis elegans}

To confirm the sensitivity of the Tsu-ACR16-like receptor to oxantel, we heterologous expressed Tsu-ACR-16 like receptor in C. elegans. We observed a decreased motility of the recombinant worms when exposed to oxantel for $24 \mathrm{~h}$, confirming the sensitivity of the TsuACR16-like receptor to oxantel. Expression of the Tsu-ACR16-like receptor was under the control of the myo3 body wall muscular promotor of C. elegans. This promotor was chosen as oxantel has shown a paralyzing effect on Trichuris spp. in vitro [44] suggesting a muscular location of the oxantel target within this genus. However, the tissue location of the Tsu-ACR16-like receptor remains to be elucidated. Our results show the ability of C. elegans to express AChR-subunits from a Clade I parasitic nematode in addition to Clade III and V (i.e. $P$. equorum and H. contortus) [36], thus confirming the C. elegans expression system to be a valuable screening tool.

\section{Sensitivity of Trichuris spp. to cholinergic drugs in vitro}

Although T. suis and T. muris are different species [45], both are used as models for T. trichiura. Trichuris muris has been extensively used to evaluate the sensitivity of the worms to several cholinergic anthelmintics in vitro $[8,44,46]$. Based on motility scores, the inhibitory concentrations $\left(\mathrm{IC}_{50}\right.$ ) have been reported for fourth-stage larvae (L4) incubated in oxantel pamoate $\left(\mathrm{IC}_{50}=2.35 \mu \mathrm{g} / \mathrm{mL}\right.$ equal to $\left.3.9 \mu \mathrm{M}\right)$ [44], third-stage larvae (L3) and adult worms incubated in pyrantel pamoate $\left(\mathrm{IC}_{50}=95.5\right.$ and $34.1 \mu \mathrm{g} / \mathrm{mL}$, respectively, equal to 161 and $57 \mu \mathrm{M})$, levamisole $\left(\mathrm{IC}_{50}=33.1\right.$ and $16.5 \mu \mathrm{g} / \mathrm{mL}$, respectively, equal to 162 and $\left.80.8 \mu \mathrm{M}\right)$ and monepantel $\left(\mathrm{IC}_{50}=78.7 \mu \mathrm{g} / \mathrm{mL}\right.$ for $\mathrm{L} 3$, equal to $\left.166 \mu \mathrm{M}\right)$ for which the latter, adult worms are not sensitive $[8,46]$. Thus, oxantel pamoate has been shown to be superior to pyrantel, levamisole and monepantel for T. muris in vitro.

\section{Pharmacokinetics of different cholinergic anthelmintics and efficacy against Trichuris spp}

Recall that the Trichuris spp. are located in the large intestines of humans and domestic animals so that concentration of anthelmintics seen by these parasites will be affected by absorption of the anthelmintic preparation along the intestine as well as the plasma concentration.

The high efficacy of oxantel pamoate could be due to the pharmacokinetic profile of the drug, as the pamoate salt limits the absorption of oxantel, increasing the concentration in the digestive tract $[18,47]$. In this context it is interesting to compare pyrantel and oxantel as these are similar in molecular structure, are both therapeutically used as pamoate salts but have very different anthelmintic properties against Trichuris spp. in vitro and in vivo (i.e. pyrantel is not effective against Trichuris spp. in vivo and in vitro). Bjørn et al. [48] have shown that pyrantel pamoate stays mostly in the intestinal lumen of pigs and has a relatively high efficacy against Oesophagostomum dentatum, a strongyle species that has the same habitat as Trichuris spp. in the large intestine [49-52]. The low efficacy of pyrantel pamoate against Trichuris spp. is therefore not caused by an absence of intestinal bioavailability of pyrantel pamoate at the site of Trichuris spp., but more due to a lower impact of pyrantel on the molecular drug-target within the worm. 
Levamisole has shown in vitro activity against adult T. muris $\left(\mathrm{IC}_{50}=80.8 \mu \mathrm{M}\right)[8]$ and $T$. suis [53], but it has a poor efficacy against Trichuris spp. infections when orally administered to humans [7] and pigs [54,55]. A plausible explanation for the low in vivo efficacy may be a low concentration of levamisole in the large intestine where Trichuris spp. are located. This is supported by observations in pigs where the concentrations of levamisole in the large intestine of pigs after oral administration of $7.5 \mathrm{mg} / \mathrm{kg}$ levamisole is $1.7-2.6 \mu \mathrm{g} / \mathrm{mL}(8.3-12.7 \mu \mathrm{M})$ [56], which is below the $\mathrm{IC}_{50}$ value $(80.8 \mu \mathrm{M})$ for adult T. muris [53]. Trichuris spp. are located partly intracellular with the anterior part buried into the mucosa [57] and the posterior part freely moveable in the lumen of the hindgut. Any anthelmintic may reach these worms via the systemic circulation as well by the gastro-intestinal tract. The plasma bioavailability of levamisole in pigs is higher after parental administration than after oral administration [56]. The effect of the route of administration on the efficacy of levamisole has been tested: it was found that parentally administered levamisole results in a higher worm count reduction (WCR $=95.5 \%$ ) than levamisole given orally (WCR $=40 \%$ ) [55]. Based on these findings, the low efficacy of levamisole stems from the less favorable pharmacokinetic profile of oral administered levamisole rather than the actual direct effect of the drug.

Monepantel is reported to have no effect on adult T. muris in vitro and in vivo [8]. Pharmacokinetic studies including monepantel and pigs, are to the knowledge of the authors not available, but the intestinal mucosa concentrations of both monepantel and the anthelmintic active metabolite monepantel sulfone [58] have been shown to decrease along the intestinal tract of sheep [59]. A suitable minimum dose of $2.5 \mathrm{mg} / \mathrm{kg}$ monepantel was selected by Kaminsky et al. [60] based on the high efficacy of the drug against parasitic nematodes situated in the lower part of the intestine. However, this dose fails to reduce T. ovis in naturally infected sheep [61].

Derquantel is ineffective against parasitic nematodes of sheep situated in the lower part of the intestine, i.e. Oesophagostomum spp. and Trichuris spp. [62] which may be related to an extensive absorption of the drug in the first half of the intestinal tract leaving insufficient drug concentrations available to parasites in the hindgut. Absorption in the first half of the intestine is predicted for sheep based on a jird-model and may therefore be different for pigs and humans.

\section{Treatment strategies for trichuriasis}

It is likely that in the shorter term, the best strategy for the control of STHs is to use existing anthelmintics in combination therapies rather than to develop new anthelmintic drugs. The rationale is to increase efficacy by using drugs with different modes of actions, to delay the development of anthelmintic resistance and to target several parasitic species (i.e. the STHs) [63]. The efficacy of oxantel pamoate has been evaluated as a monotherapy or in combination with a range of other anthelmintics such as albendazole [21], mebendazole, pyrantel pamoate [64], tribendimidine [65] and moxidectin [66]. For T. trichiura, the greatest efficacy has been calculated for co-administration of oxantel pamoate and albendazole, whereas the triple combination oxantel pamoate, pyrantel pamoate and albendazole showed the highest efficacy to all the STHs [63]. Another strategy for the control of STHs is to evaluate more recent veterinary anthelmintic drugs such as emodepside [63], which due to its high efficacy against T. vulpis, even as a single-dose treatment (Profender tablets for dogs) [67], has been approved for the treatment of trichuriasis in dogs [68]. Emodepside has recently shown promising results when tested in vitro on T. muris, and the hookworms Ancylostoma ceylanicum, Necator americanus, and in vivo in animal models infected with the above mentioned parasitic species [69]. Thus, emodepside is a promising drug candidate for the treatment of not only trichuriasis, but for 
STHs. We point out that the recommendations for treatment of trichuriasis in both human and veterinary medicine, are for the benzimidazoles, administration on 3 consecutive days. $[70,71]$ However, the 3 -day treatment is not compatible with mass drug administration programs for the control of STHs [72] which require single-dose treatments.

In conclusion, the discovery of the Tsu-O-AChR provides new insights for the high efficacy and specificity of oxantel on whipworms, and provide us with an example of an anthelmintic, that due to its narrow-spectrum will have a lower impact on non-target nematode species. The advantage of such an anthelmintic is the reduced risk of inducing anthelmintic resistance in other parasitic nematode species, and a lower impact on the environmental biodiversity after drug expulsion from the host (i.e. primarily animal hosts).

\section{Material and methods}

\section{Ethic statement}

The worm material used in this study was obtained during a previous described study [73] performed at the Experimental Animal Unit, University of Copenhagen, Denmark according to the national regulations of the Danish Animal Inspectorate (permission no. 2015-15-020100760). The neurologic tissue from $X$. laevis was obtained from one adult female, which was anaesthetized by submersion into a tricaine solution (ethyl 3-aminobenzoate methanesulfonate, $2 \mathrm{~g} / \mathrm{L}$ ) and subsequently decapitated. All procedures involving live material were performed according to the national regulations of the Danish National Animal Experiments Inspectorate (permission no. 2015-15-0201-00560).

\section{Drugs}

All drugs except 3-bromocytisine, DH $\beta E, \alpha-B T X$ and derquantel were purchased at SigmaAldrich (Copenhagen, DK). 3-bromocytisine, DH $\beta E$ and $\alpha$-BTX were obtained from Tocris Bioscience (Abingdon, UK) and derquantel was purchased at Cayman Chemicals (Ann Abor, MI, USA). Stock solutions of drugs were made in either Kulori medium or DMSO (100\%) and stored at -20 or $5^{\circ} \mathrm{C}$ (i.e. ACh) until use. Before use, stock solutions were dissolved in Kulori medium with a maximum final concentration of DMSO of $0.1 \%$.

\section{Bioinformatics and sequence analysis}

The Asu-ACR-16 (accession number AKR16139) and the Cel-ACR-16 (accession number NP505207) were used as queries in database searches for Trichuris suis ACR-16 (Tsu-ACR-16) and ACR-16s from other Clade I parasitic nematodes (i.e. Trichuris spp. and Trichinella spiralis) in the protein-protein BLAST (BLASTp) service at the National Center for Biotechnology Information (NCBI) service [74]. Cel-ACR-16 and Cel-ACR-19 were used in an alignment with the identified putative ACR-16 sequences from Clade I parasitic nematodes. The accession numbers of the sequences used for the alignment are:

Caenorhabditis elegans: ACR-16 NP_505207, ACR-19 NP_001129756. Trichuris suis: putative ACR-16 KFD48832.1 putative ACR-19 KFD70086.1. Trichuris trichiura: putative ACR-16 CDW52185; putative ACR-19 CDW53523. Trichuris muris: putative ACR-16 WBGene00290200; putative ACR-19 WBGene00291941. Trichuris spiralis: putative ACR-16 KRY38920.1, putative ACR-19 KRY27533.1.

Signal peptide was predicted using the SignalP 4.1 server [75] and the transmembrane regions were predicted using the TMHMM version 2 server [76]. Deduced amino-acid sequences were aligned using MUSCLE. Phylogenetic analysis was performed on deduced amino-acid sequences. Maximal likelihood phylogeny reconstruction was performed using 
PhyML V20120412 (https://github.com/stephaneguindon/phyml-downloads/releases) and the significance of internal tree branches was estimated using bootstrap resampling of the dataset 100 times. The accession numbers sequences used for the analysis are:

Caenorhabditis elegans: ACR-7 NP_495647; ACR-8 NP_509745; ACR-9 NP_510285; ACR-10 NP_508692; ACR-11 NP_491906; ACR-12 NP_510262; ACR-14 NP_495716; ACR15 NP_505206; ACR-16 NP_505207; ACR-19 NP_001129756; EAT-2 NP_496959; LEV-1 NP_001255705; UNC-29 NP_492399; UNC-38 NP_491472; UNC-63 NP_491533.

Haemonchus contortus: ACR-16 MH806893. Soboliphyme baturini: acr-16-like VDP07835.1. Steinernema glaseri: ACR-16 KN173365.1. Steinernema feltiae: ACR-19 KN166031.1.

Toxocara canis: ACR-16 VDM44142.1; ACR-19 VDM36763.1. Parascaris equorum: ACR26 KP756902; ACR-27 KP756903. Trichuris suis: ACR-16-like KFD48832; ACR-19 KFD70086. Trichuris muris: ACR-16-like WBGene00290200; ACR-19 WBGene00291941. Trichuris trichiura: ACR-16-like CDW52185; ACR-19 CDW53523. Trichinella spiralis: ACR-16-like KRY38920.1; ACR-19 KRY27533.

\section{cDNA synthesis}

Worm material was kept in RNA later (Sigma-Aldrich, Copenhagen, DK) at $-20^{\circ} \mathrm{C}$ until use. Total RNA was extracted from whole adult T. suis males and females using TRIzol LS Reagent (Invitrogen). For each isolation, 15 worms were used. The RNA was DNAse treated (Invitrogen). The whole brain of one X. laevis frog was used to extract RNA using Tri Reagent; (MRC. Inc; US) and $M$ tubes in an OctoMacs homogenizer machine (Milteny, Germany) following the manufacturer' protocol. The isolated RNA was DNAse treated using the RNeasy MinElute Cleanup kit (Qiagen, Germany). The quantity and quality of RNA from T. suis and X. laevis was assessed by OD measurement in a Nanodrop spectrophotometer (Thermo Scientific, Demark) and by visual inspection in an agarose gel (1\%). First strand cDNA was synthesised from $2.5 \mu \mathrm{g}$ of RNA from T. suis whole worms and brain RNA from X. laevis using SuperScript IV VILO Master Mix (Invitrogen) according to manufacturer's protocol.

\section{PCR and cloning of a full-length T. suis ACR-16 subunit and Xla-RIC-3}

To amplify the full-length coding sequence of the Tsu-acr-16-like subunit, we performed a direct PCR using a specific primer pair, containing the BamHI and the NotI restriction enzyme sites and 5 additional nucleotides (Tsu-acr-16-F-5'- GAATC-BamHI-ATGCGGCCGATAATTTTCCTC-3' and Tsu-acr-16-R- 5'-ACGTT NotI TCACACAGTTAAATGGGGAGAAC-3'). The specific primers were designed using the putative Tsu-acr-16-like sequence in Wormbase under gene number M514_10316 and were designed to target the 5'- and the 3'end of the putative Tsu-acr-16-like cDNA sequence. The specific primer pair used to amplify the Xla-ric-3 sequence are described elsewhere [32]. Restriction enzyme sites (BamHI and NotI) were included to facilitate ligation into the expression vector pXOOM [77]. PCR amplifications were performed with Platinum SuperFi Green PCR Master Mix (Invitrogen) following the manufacturer' recommendations. Amplicons were evaluated by gel electrophoresis, purified with QIAquick Gel Extraction Kit (Qiagen), cloned into pXOOM and sequenced. A positive clone of Tsu-acr-16-like subunit and Xla-ric-3 was selected and linearized with the restriction enzyme NheI before in vitro transcription using the mMessage mMachine T7 Transcription Kit (Ambion). In parallel, cRNAs for the RIC-3 homologs from A. suum, H. contortus and C. elegans were also synthesized. The cRNAs were purified using MEGAclear (Thermo Scientific, Demark). Quantity and quality of cRNAs was evaluated by OD measurement in a 
Nanodrop spectrophotometer (Thermo Scientific, Demark) and by visual inspection in an agarose gel (1\%).

\section{Microinjection of Xenopus laevis oocytes}

Xenopus laevis oocytes were obtained from EcoCyte Bioscience (Castrop-Rauxel, Germany) and kept at $19^{\circ} \mathrm{C}$ in Kulori medium $\left(90 \mathrm{mM} \mathrm{NaCl}, 4 \mathrm{mM} \mathrm{KCl}, 1 \mathrm{mM} \mathrm{MgCl} 2,1 \mathrm{mM} \mathrm{CaCl}_{2}, 5\right.$ mM HEPES, pH:7.4) until injection. Oocytes were injected with $50 \mathrm{nl}$ of cRNA in RNAse-free water using a microinjector (Nanojet, Drummond Broomal, PA, USA). To test ric-3 effects on the receptor expression, $25 \mathrm{ng}$ Tsu-acr-16-like cRNA was injected alone or with $5 \mathrm{ng}$ of either of the following ric-3 cRNAs: Asu-ric-3, Xla-ric-3, Hco-ric-3.1 or Cel-ric-3. To exclude endogenous nAChR expression induced by Asu-ric-3, $5 \mathrm{ng}$ Asu-ric-3 was injected alone. These amounts of cRNA were chosen in order to compare the drug-potency results of the Tsu-ACR16-like receptor with that of Asu-ACR-16[29]. Only half (i.e. $12.5 \mathrm{ng}$ Tsu-acr-16-like cRNA

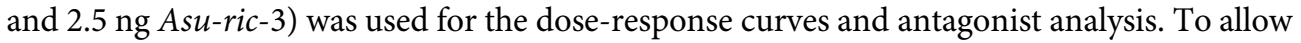
for receptor expression, the injected oocytes were incubated in Kulori medium at $19^{\circ} \mathrm{C}$ for 3-7 days and the Kulori medium was changed daily.

\section{Two-electrode voltage clamp of Xenopus laevis oocytes}

Two-electrode voltage-clamp (TEVC) recordings were obtained using an Oocyte Clamp Amplifier OC-725 B (Warner Instruments Corp., USA) connected to an Axon Digidata 1440A digitizer (Axon Instruments, Molecular Devices, USA) and was performed at $\sim 19^{\circ} \mathrm{C}$ under continuous flow of Kulori medium with the oocytes clamped at $-60 \mathrm{mV}$. Data were sampled at $2 \mathrm{kHz}$ using the pClamp 10.4 acquisition software (Axon Instruments, Molecular Devices, USA). The microelectrodes were pulled from glass capillaries (TW 120.3, World precision instruments, USA) on a programmable micropipette puller (Narishige, Japan). The resistance when filled with $3 \mathrm{M} \mathrm{KCl}$ ranged from 0.5 to $1.5 \mathrm{M} \Omega$. $\mathrm{Ag} / \mathrm{AgCl}$ reference electrodes were connected to the bath with agar bridges. For a minimum of 4 hours prior to recording, all oocytes were incubated in BAPTA-AM at a final concentration of $100 \mu \mathrm{M}$ to chelate intracellular $\mathrm{Ca}^{2+}$ ions and hereby prevent activation of endogenous calcium activated chloride channels during recordings. For each experiment, 6 positive- and 6 negative control oocytes were exposed to $100 \mu \mathrm{M}$ ACh for $10 \mathrm{~s}$ on the day of each experimentation. Recordings of oocytes co-injected with Tsu-acr-16-like and Asu-ric-3 cRNAs were used as positive controls, and recording of non-injected oocytes as negative controls. The quality of each oocyte was evaluated before drug exposure, i.e. only injected oocytes with a membrane potential between -40 to $-60 \mathrm{mV}$ before clamping and a current injection below $0.1 \mu \mathrm{A}$ after clamping were included in the experiments. To determine the reversal potential for the activated receptor in presence of low $(1 \mathrm{mM})$ and high $(10 \mathrm{mM}) \mathrm{CaCl}_{2}$ concentrations, the oocytes were exposed to $100 \mu \mathrm{M} \mathrm{ACh}$ and subsequently currents were measured at voltage between- $40 \mathrm{mV}$ to $40 \mathrm{mV}(10 \mathrm{mV}$ increments). We cannot exclude that some oocytes exposed to non-activating drugs were poorly expressing oocytes as we did not apply ACh after the test drug exposure. However, with the number of oocytes tested from at least 3 batches of eggs, we find it most unlikely that this would have an impact on the overall results.

\section{Drug-potency-tests}

All agonists were used at a final concentration of $100 \mu \mathrm{M}$ and were tested in 3-4 experiments using 3-4 different batches of oocytes batches. For each experiment, 6 oocytes were tested per drug. For each experiment, 6 oocytes were exposed to $100 \mu \mathrm{M} \mathrm{ACh}$ for $10 \mathrm{~s}$, and all other responses in the same experiment, were normalized to the mean response of these controls. As 
the ACR-16 of the parasitic nematode A. suum has been reported to respond to a $10 \mathrm{~s}$ application period of oxantel [29], we applied the same application period in our studies for comparison. Initial experiments showed a consistent decrease in the response to $100 \mu \mathrm{M}$ ACh when applied repeatedly, even after washing periods for up to $5 \mathrm{~min}$ between agonist applications. An example of this can be seen in Fig 7B where the same oocytes were exposed to $100 \mu \mathrm{M}$ ACh 3 times separated by washing periods of $5 \mathrm{~min}$. Therefore, each drug was tested on oocytes not previously exposed to ACh $(100 \mu \mathrm{M})$. The total number of oocytes examined per drug was: $n=23$ for oxantel, $n=16$ for pyrantel, $n=15$ for epibatidine, $n=16$ for nicotine, $n=15$ for 3 bromocytisine, $n=16$ for DMPP, $n=17$ for morantel, $n=17$ for cytisine and $n=15$ for levamisole. Each drug was applied for $10 \mathrm{~s}$ followed by wash off until the current had returned to pre-stimulation values.

\section{Dose-response studies}

The dose-response studies were in total performed on 3 different oocyte batches. For acetylcholine the number of measurements per drug concentration were 9 . For oxantel the number of measurements per drug concentration were as follows: $0.3 \mu \mathrm{M}, n=6 ; 0.1 \mu \mathrm{M}, n=6 ; 3 \mu \mathrm{M}$, $n=6 ; 3 \mu \mathrm{M}, n=6 ; 10 \mu \mathrm{M}, n=15 ; 30 \mu \mathrm{M}, n=12 ; 100 \mu \mathrm{M}, n=13 ; 300 \mu \mathrm{M}, n=14$. For pyrantel $n$ per drug concentration were: $1 \mu \mathrm{M}, n=6 ; 3 \mu \mathrm{M}, n=6 ; 10 \mu \mathrm{M}, n=6 ; 30 \mu \mathrm{M}, n=6 ; 100 \mu \mathrm{M}$, $n=15 ; 300 \mu \mathrm{M}, n=23 ; 1000 \mu \mathrm{M}, n=12 ; 3000 \mu \mathrm{M}, n=20$. For each experiment, 6 oocytes were exposed to $300 \mu \mathrm{M} \mathrm{ACh}$ for $10 \mathrm{~s}$, and all other responses in the same experiment, were normalized to the mean response of these positive controls. The ACh concentration of $300 \mu \mathrm{M}$ was used to reach the maximal activation of the Tsu-ACR-16-like receptor. Each drug and drug concentration were tested as described for the drug-potency-tests.

\section{Antagonists}

The effects of the antagonists DH $\beta E$, derquantel and $\alpha$-BTX $(10 \mu \mathrm{M})$ were examined in the presence $100 \mu \mathrm{M}$ ACh as previously described for Asu-ACR-16 [29]. In short, X. laevis oocytes co-injected with Tsu-acr-16-like- and Xla-ric-3 cRNA were sequentially superfused with ACh for $10 \mathrm{~s}$, then $\mathrm{ACh}+$ antagonist for $10 \mathrm{~s}$, and finally with ACh for $10 \mathrm{~s}$. For $\alpha$-BTX a five-step protocol including a pre-incubation $(10 \mathrm{~s})$ with the antagonist $(10 \mu \mathrm{M})$ was used with ACh $(100 \mu \mathrm{M})$. Xenopus laevis oocytes, co-injected with Tsu-acr-16-like- and Xla-ric-3 cRNAs, were exposed to: i) a control application of $100 \mu \mathrm{M}$ ACh for $10 \mathrm{~s}$ (first application); ii) followed by a wash-off period of $5 \mathrm{~min}$; iii) then by an application of $10 \mu \mathrm{M} \alpha$-BTX for $10 \mathrm{~s}$, immediately followed by $100 \mu \mathrm{M} \mathrm{ACh}$ and the continued presence of $\alpha$-BTX for $10 \mathrm{~s}$ (second application); iv) then a wash-off period of $5 \mathrm{~min}$; v) and finally an application of ACh for $10 \mathrm{~s}$ (third application). Control oocytes were exposed to ACh for $10 \mathrm{~s}$ in 3 consecutive steps, each separated by a wash-off period of $5 \mathrm{~min}$. For each antagonist, $n=6-8$.

\section{Electrophysiological data and statistically analysis}

All acquired electrophysiological data were analysed with Clampfit 10.7 (Molecular Devices, Sunnyvale, CA, USA) and GraphPad Prism 8 (GraphPad Software, La Jolla, CA, USA) and from all experiments, peak currents from BAPTA-AM-incubated oocytes were measured after application of drugs. For the auxiliary protein (RIC-3) test, the group mean current of oocytes co-injected with Xla-ric-3 and Tsu-acr-16-like cRNAs in response to $100 \mu \mathrm{M}$ ACh was set to $100 \%$, and all other responses were normalized to this. The relative means were statistical analysed using a non-parametric Kruskal-Wallis Test and $P<0.05$ was considered significant. For the drug-potency-test, peak currents of drugs were normalized to the peak current measured in the presence of $100 \mu \mathrm{M} \mathrm{ACh}$ and was expressed as mean \pm SEM. Data was tested for 
normality using the D'Agostino-Pearson normality test. Drug-group means were statistical analysed using One-Way ANOVA with a Turkey's Multiple Comparison Test where $P<0.05$ was considered significant.

For the dose-response relationships, and for each experiment, 6 oocytes were exposed to $\mathrm{ACh}(300 \mu \mathrm{M})$ for $10 \mathrm{~s}$, and all other drug responses in the same experiment, were normalized to the mean response of these controls. The normalized current as a function of drug concentration allowed fitting the dose-response curves with a Hill equation, using nonlinear regression analysis with a variable slope model in GraphPad Prism 8. The following equation was used:

$$
I_{\text {rel }}=I_{\text {min }}+\left(I_{\max }-I_{\min }\right) /\left(1+10^{\wedge}\left(\left(\log E C_{50}-[D]\right) * n H\right)\right),
$$

where $I_{\text {rel }}$ is the mean relative current, $I_{\max }$, is the relative current obtained at saturating agonist concentration, $I_{\min }$ is the relative current obtained at agonist concentration $0 \mu \mathrm{M}, E C_{50}$ is the concentration of agonist resulting in $50 \%$ of the maximal current response, $[D]$ is the drug concentration and $n_{\mathrm{H}}$ is the Hill coefficient. $I_{\max }, E C_{50}$ and $n_{\mathrm{H}}$ were fitted as free parameters whereas $I_{\min }$, was constrained to 0 .

For the antagonist test with $\alpha$-BTX, the current response of $\alpha$-BTX and ACh in the continued presence of $\alpha$-BTX (second application) was normalized to the first response at $100 \mu \mathrm{M}$ ACh (first application) which was set to 1 . The group mean of the $\alpha$-BTX response were statistical analysed using One-Way ANOVA with a Dunnett's test.

\section{Caenorhabditis elegans experiments}

Wildtype worms N2 were used to express the Tsu-ACR-16-like receptor under the control of the myosin promotor present in the plasmid pmyo3, pPD96.52 (Addgen). The pmyo3 plasmid was co-injected at $60 \mathrm{ng} / \mu \mathrm{L}$ with plasmid pPD118.33_pmyo2::gfp (Addgen) at $30 \mathrm{ng} / \mu \mathrm{L}$ into the gonads of young adult hermaphrodites worms as previously described [78]. The pPD118.33_pmyo2::gfp was used as a transformation marker and three stable recombinant $C$. elegans lines were generated. The motility of all lines was determined by counting the thrashes of individual gravid adult worms for $30 \mathrm{~s}$. All thrashing assays were performed in 96-well plates containing M9 buffer with $0.1 \%$ BSA, either with or without $500 \mu \mathrm{M}$ of oxantel. The basal motility of wt N2 and each of the recombinant lines was establish after 10 min equilibration time in M9 buffer. The effect of oxantel on the worms was evaluated after $24 \mathrm{~h}$ incubation in M9 buffer with $500 \mu \mathrm{M}$ of oxantel. Wild type $\mathrm{N} 2$ and each of the recombinant lines not exposed to $500 \mu \mathrm{M}$ oxantel for $24 \mathrm{~h}$ were used as negative controls. The motility of each line was statistically analyzed using Kruskal-Wallis- and Wilcoxon's test.

\section{Supporting information}

S1 Fig. Distance tree showing relationships of the ACR-16-like acetylcholine receptor (AChR) subunits from Clade I nematode species, with other AChR subunits from the ACR-16 group from nematode species representative from Clade III, Clade IV, and Clade

V. NJ-Tree was built upon an alignment of AChR subunit deduced amino-acid sequences. The tree was rooted with the $C$. elegans UNC-63 sequence. Scale bar represents the number of substitutions per site. Bootstrap values (1000 replicates) are indicated on branches. Accession numbers for sequences used in the analysis are provided in Material and Methods section. Nematode clades refer to Blaxter et al. 1998 [1]. AChR subunit sequences from Clade I species are highlighted in red, AChR subunit sequences from Clade III species are highlighted in blue, AChR subunit sequences from Clade V species are highlighted in pink (in black for C. elegans). Cel, Hco, Sba, Sgl, Sfe, Tca, Tsp, Tsu, Ttr and Tmu refer to: Caenorhabditis elegans, 
Haemonchus contortus, Soboliphyme baturini, Steinernema glaseri, Steinernema feltiae, Toxocara canis, Trichinella spiralis, Trichuris suis, Trichuris trichiura, and Trichuris muris respectively.

S2 Fig. Desensitization kinetics of Tsu-ACR16-like receptor. A representative response of the Tsu-ACR16-like receptor to $1 \mathrm{~min}$ exposure of $100 \mu \mathrm{M}$ ACh. The Tsu-ACR16-like receptor is characterized by a slow-desensitization kinetic as compared to Asu-ACR-16 [29] and PeqACR-16 [33].

S3 Fig. Viability of N2 and recombinant Caenorhabditis elegans lines after 24 hours. Boxplot depicts number of thrashes/30 sec of worms in M9 after $24 \mathrm{~h}$. The number of thrashes were not significant between neither of the lines when oxantel was not included in the M9 buffer.

S1 Video. The movie shows the motility of adult wild type N2 (absence of a green fluorescent pharynx) and recombinant Caenorhabditis elegans harbouring the Tsu-acr-16-like receptor (green fluorescent pharynx) after 24 hours incubation in M9 buffer with $500 \mu \mathrm{M}$ oxantel. Note the lower motility of the recombinant worms.

(MP4)

\section{Acknowledgments}

Authors would like to thank Richard Martin at Iowa State University, USA for providing the Asu-ACR-16 and Asu-RIC-3. In addition, the authors wish to thank Vibeke Grøsfjeld Christensen at the Department for Veterinary and Animal Sciences, University of Copenhagen for technical assistance.

\section{Author Contributions}

Conceptualization: Tina V. A. Hansen, Richard J. Martin.

Data curation: Tina V. A. Hansen, Elise Courtot.

Formal analysis: Tina V. A. Hansen, Cédric Neveu, Elise Courtot.

Investigation: Tina V. A. Hansen, Elise Courtot, Dan A. Klaerke.

Methodology: Tina V. A. Hansen, Susanna Cirera, Elise Courtot, Claude L. Charvet, Kirstine Calloe, Dan A. Klaerke, Richard J. Martin.

Project administration: Tina V. A. Hansen.

Resources: Richard J. Martin.

Software: Dan A. Klaerke, Richard J. Martin.

Supervision: Susanna Cirera, Cédric Neveu, Kirstine Calloe, Dan A. Klaerke, Richard J. Martin.

Validation: Cédric Neveu, Claude L. Charvet, Dan A. Klaerke.

Writing - original draft: Tina V. A. Hansen, Cédric Neveu, Elise Courtot.

Writing - review \& editing: Tina V. A. Hansen, Susanna Cirera, Cédric Neveu, Claude L. Charvet, Kirstine Calloe, Dan A. Klaerke, Richard J. Martin. 


\section{References}

1. Blaxter ML, De Ley P, Garey JR, Liu LX, Scheldeman P, Vierstraete A, et al. A molecular evolutionary framework for the phylum Nematoda. Nature. 1998; 392(6671):71-5. https://doi.org/10.1038/32160 PMID: 9510248.

2. James SL, Abate D, Abate KH, Abay SM, Abbafati C, Abbasi N, et al. Global, regional, and national incidence, prevalence, and years lived with disability for 354 Diseases and Injuries for 195 countries and territories, 1990-2017:A systematic analysis for the Global Burden of Disease Study 2017. Lancet. 2018; 392(10159):1789-1858. https://doi.org/10.1016/S0140-6736(18)32279-7 PMID: 30496104.

3. Stephenson LS, Latham MC, Ottesen EA. Malnutrition and parasitic helminth infections. Parasitology;2000; 121, Suppl S23-S38. https://doi.org/10.1017/s0031182000006491 PMID: 11386688.

4. Hall A, Hewitt G, Tuffrey V, Silva N. A review and meta-analysis of the impact of intestinal worms on child growth and nutrition. Matern Child Nutr. 2008; 4 Suppl 1(Suppl 1):118-236. https://doi.org/10. 1111/j.1740-8709.2007.00127.x PMID: 18289159.

5. Keiser J, Utzinger J. Efficacy of current drugs against soil-transmitted helminth infections:systematic review and meta-analysis. JAMA. 2008; 299(16):1937-48. https://doi.org/10.1001/jama.299.16.1937 PMID: 18430913.

6. Belizario VY, Amarillo ME, Leon WU, Reyes AE, Bugayong MG. Macatangay BJC. A comparison of the efficacy of single doses of albendazole, ivermectin, and diethylcarbamazine alone or in combinations against Ascaris and Trichuris spp. Bull World Health Organ. 2003; 81(1):35-42. PMID: 12640474.

7. Albonico M, Bickle Q, Ramsan M, Montresor A, Savioli L, Taylor M. Efficacy of mebendazole and levamisole alone or in combination against intestinal nematode infections after repeated targeted mebendazole treatment in Zanzibar. Bull World Health Organ. 2003; 81(5):343-52. PMID: 12856052.

8. Tritten L, Silbereisen A, Keiser J. In vitro and In vivo efficacy of monepantel(AAD 1566) against laboratory models of human intestinal nematode infections. PLoS Negl Trop Dis. 2011; 5(12):e1457. https:// doi.org/10.1371/journal.pntd.0001457 PMID: 22216366.

9. Steinmann P, Utzinger J, Du Z, Jiang J, Chen J, Hattendorf J, et al. Efficacy of single-dose and tripledose albendazole and mebendazole against soil-transmitted helminths and Taenia spp.:a randomized controlled trial. PLoS One. 2011; 6(9):e25003. https://doi.org/10.1371/journal.pone.0025003 PMID: 21980373

10. Knopp S, Mohammed KA, Speich B, Hattendorf J, Khamis IS, Khamis AN, et al. Albendazole and mebendazole administered alone or in combination with ivermectin against Trichuris trichiura:a randomized controlled trial. Clin Infect Dis. 2010; 51(12):1420-8. https://doi.org/10.1086/657310 PMID: 21062129.

11. Namwanje $\mathrm{H}$, Kabatereine NB, Olsen A. Efficacy of single and double doses of albendazole and mebendazole alone and in combination in the treatment of Trichuris trichiura in school-age children in Uganda. Trans R Soc Trop Med Hyg. 2011; 105(10):586-90. https://doi.org/10.1016/j.trstmh.2011.07. 009 PMID: 21885077.

12. Olsen $A$, Namwanje $H$, Nejsum $P$, Roepstorff A, Thamsborg SM. Albendazole and mebendazole have low efficacy against Trichuris trichiura in school-age children in Kabale District, Uganda. Trans R Soc Trop Med Hyg. 2009; 103(5):443-6. https://doi.org/10.1016/j.trstmh.2008.12.010 PMID: 19201005.

13. Sangster NC, Cowling A, Woodgate RG. Ten Events That Defined Anthelmintic Resistance Research. Trends Parasitol. 2018; 34(7):553-63. https://doi.org/10.1016/j.pt.2018.05.001 PMID: 29803755.

14. Diawara A, Halpenny CM, Churcher TS, Mwandawiro C, Kihara J, Kaplan RM, et al. Association between response to albendazole treatment and beta -tubulin genotype frequencies in soil-transmitted helminths. PLoS Negl Trop Dis. 2013;30; 7(5):e2247. https://doi.org/10.1371/journal.pntd.0002247 PMID: 23738029.

15. Krücken J, Fraundorfer K, Mugisha JC, Ramüncke S, Sifft KC, Geus D, et al. Reduced efficacy of albendazole against Ascaris lumbricoides in Rwandan schoolchildren. Int J Parasitol Drugs Drug Resist. 2017; 7(3):262-271. https://doi.org/10.1016/j.jpddr.2017.06.001 PMID: 28697451.

16. Martin RJ, Clark CL, Trailovic SM, Robertson AP. Oxantel is an N-type(methyridine and nicotine) agonist not an L-type(levamisole and pyrantel) agonist:classification of cholinergic anthelmintics in Ascaris. Int J Parasitol. 2004; 34(9):1083-90. https://doi.org/10.1016/j.ijpara.2004.04.014 PMID: 15313135.

17. McFarland JW, Howes HL. Novel anthelmintic agents. 6. Pyrantel analogs with activity against whipworm. J Med Chem. 1972; 15(4):365-8. https://doi.org/10.1021/jm00274a008 PMID: 4623095.

18. Sheehan DJ, Sheehan SM, Marchiondo AA. Discovery and Chemistry of Pyrantel, Morantel and Oxantel. Pyrantel Parasiticide Therapy in Humans and Domestic Animals. Edited by:Alan A. Marchiondo. Academic Press;2016. pp. 1-19. Available from: https://doi.org/10.1016/B978-0-12-801449-3.00012-0.

19. Lee EL, lyngkaran N, Grieve AW, Robinson MJ, Dissanaike AS. Therapeutic evaluation of oxantel pamoate(1, 4, 5, 6-tetrahydro-1-methyl-2-[trans-3-hydroxystyryl] pyrimidine pamoate) in severe 
Trichuris trichiura infection. Am J Trop Med Hyg. 1976; 25(4):563-7. https://doi.org/10.4269/ajtmh. 1976.25.563 PMID: 961973.

20. Garcia EG. Treatment for trichuriasis with oxantel. Am J Trop Med Hyg. 1976; 25(6):914-5. https://doi. org/10.4269/ajtmh.1976.25.914 PMID: 1008134.

21. Speich B, Ame SM, Ali SM, Alles R, Huwyler J, Hattendorf J, et al. Oxantel pamoate-albendazole for Trichuris trichiura infection. N Engl J Med. 2014;13; 370(7):610-20. https://doi.org/10.1056/ NEJMoa1301956 PMID: 24521107.

22. Moser W, Ali SM, Ame SM, Speich B, Puchkov M, Huwyler J, et al. Efficacy and safety of oxantel pamoate in school-aged children infected with Trichuris trichiura on Pemba Island, Tanzania:a parallel, randomised, controlled, dose-ranging study. Lancet Infect Dis. 2016; 16(1):53-60. https://doi.org/10.1016/ S1473-3099(15)00271-6 PMID: 26388169.

23. World Health Organization. Assessing the efficacy of anthelminthic drugs against schistosomiasis and soil-transmitted helminthiases. World Health Organization;2013. Available from: https://apps. who.int/ iris/handle/10665/79019.

24. Wolstenholme AJ, Neveu C. The interactions of anthelmintic drugs with nicotinic receptors in parasitic nematodes. Emerg Top Life Sci 2017; 1(6):667-673. Available from: https://doi.org/10.1042/ ETLS20170096 PMID: 33525839

25. Albuquerque EX, Pereira EFR, Alkondon M, Rogers SW. Mammalian Nicotinic Acetylcholine Receptors:From Structure to Function. Physiol Rev. Ame2009; 89(1):73-120. https://doi.org/10.1152/ physrev.00015.2008 PMID: 19126755.

26. Holden-Dye L, Joyner M, O'Connor $\mathrm{V}$, Walker RJ. Nicotinic acetylcholine receptors:a comparison of the nAChRs of Caenorhabditis elegans and parasitic nematodes. Parasitol Int. 2013; 62(6):606-15. https:// doi.org/10.1016/j.parint.2013.03.004 PMID: 23500392.

27. Qian H, Martin RJ, Robertson AP. Pharmacology of N-, L-, and B-subtypes of nematode nAChR resolved at the single-channel level in Ascaris suum. FASEB J. 2006; 20(14):2606-8. https://doi.org/10. 1096/fj.06-6264fje PMID: 17056760.

28. Ballivet M, Alliod C, Bertrand S, Bertrand D. Nicotinic Acetylcholine Receptors in the Nematode Caenorhabditis elegans. J Mol Biol. 1996; 258(2):261-9. https://doi.org/10.1006/jmbi.1996.0248 PMID: 8627624.

29. Abongwa M, Buxton SK, Courtot E, Charvet CL, Neveu C, McCoy CJ, et al. Pharmacological profile of Ascaris suum ACR-16, a new homomeric nicotinic acetylcholine receptor widely distributed in Ascaris tissues. Br J Pharmacol. 2016; 173(16):2463-77. https://doi.org/10.1111/bph.13524 PMID: 27238203.

30. Raymond V, Mongan N, Sattelle D. Anthelmintic actions on homomer-forming nicotinic acetylcholine receptor subunits:chicken $\alpha 7$ and ACR-16 from the nematode Caenorhabditis elegans. Neuroscience. 2000; 101(3):785-91. https://doi.org/10.1016/s0306-4522(00)00279-7 PMID: 11113327.

31. Mongan NP, Jones AK, Smith GR, Sansom MSP, Sattelle DB. Novel $\alpha 7$-like nicotinic acetylcholine receptor subunits in the nematode Caenorhabditis elegans. Protein Sci. 2002; 11(5):1162-71. https:// doi.org/10.1110/ps.3040102 PMID: 11967372.

32. Bennett HM, Lees K, Harper KM, Jones AK, Sattelle DB, Wonnacott S, et al. Xenopus laevis RIC-3 enhances the functional expression of the $C$. elegans homomeric nicotinic receptor, ACR-16, in Xenopus oocytes. J Neurochem. 2012; 123(6):911-8. https://doi.org/10.1111/jnc.12013 PMID: 22970690.

33. Charvet CL, Guégnard F, Courtot E, Cortet J, Neveu C. Nicotine-sensitive acetylcholine receptors are relevant pharmacological targets for the control of multidrug resistant parasitic nematodes. Int $\mathrm{J}$ Parasitol Drugs Drug Resist. 2018; 8(3):540-9. https://doi.org/10.1016/j.jpddr.2018.11.003 PMID: 30502120.

34. Courtot E, Charvet CL, Beech RN, Harmache A, Wolstenholme AJ, Holden-Dye L, et al. Functional Characterization of a Novel Class of Morantel-Sensitive Acetylcholine Receptors in Nematodes. PLOS Pathog. 2015; 11(12):e1005267. https://doi.org/10.1371/journal.ppat.1005267 PMID: 26625142.

35. Duguet TB, Charvet CL, Forrester SG, Wever CM, Dent JA, Neveu C, et al. Recent Duplication and Functional Divergence in Parasitic Nematode Levamisole-Sensitive Acetylcholine Receptors. PLoS Negl Trop Dis. 2016; 10:4826. https://doi.org/10.1371/journal.pntd.0004826 PMID: 27415016.

36. Blanchard A, Guégnard F, Charvet CL, Crisford A, Courtot E, Sauvé C, et al. Deciphering the molecular determinants of cholinergic anthelmintic sensitivity in nematodes: When novel functional validation approaches highlight major differences between the model Caenorhabditis elegans and parasitic species. PLOS Pathog. 2018; 14(5):e1006996. https://doi.org/10.1371/journal.ppat.1006996 PMID: 29719008.

37. Sleigh JN. Functional analysis of nematode nicotinic receptors. Biosci Horizons, Int J Stud Research. 2010; 3(1):29-39. https://doi.org/10.1093/biohorizons/hzq005 
38. Williamson SM, Walsh TK, Wolstenholme AJ. The cys-loop ligand-gated ion channel gene family of Brugia malayi and Trichinella spiralis:A comparison with Caenorhabditis elegans. Invertebr Neurosci. 2007; 7(4):219-26. https://doi.org/10.1007/s10158-007-0056-0 PMID: 17952476.

39. Dale VME, Martin RJ. Oxantel-activated single channel currents in the muscle membrane of Ascaris suum. Parasitology. 1995; 110(Pt 4):437-48. https://doi.org/10.1017/s0031182000064775 PMID: 7538657.

40. Robertson SJ, Pennington AJ, Mark Evans A, Martin RJ. The action of pyrantel as an agonist and an open channel blocker at acetylcholine receptors in isolated Ascaris suum muscle vesicles. Eur J Pharmacol. 1994; 271(2-3):273-82. https://doi.org/10.1016/0014-2999(94)90784-6 PMID: 7535704.

41. Touroutine D, Fox RM, Stetina SE. von, Burdina A, Miller DM III, et al. acr-16 Encodes an essential subunit of the levamisole-resistant nicotinic receptor at the Caenorhabditis elegans neuromuscular junction. J Biol Chem. 2005; 280(29):27013-21. https://doi.org/10.1074/jbc.M502818200 PMID: 15917232.

42. Hansen CP, Jensen AA, Christensen JK, Balle T, Liljefors T, Frølund B. Novel acetylcholine and carbamoylcholine analogues:Development of a functionally selective $\alpha 4 \beta 2$ nicotinic acetylcholine receptor agonist. J Med Chem. 2008; 51(23):7380-95. https://doi.org/10.1021/jm701625v PMID: 18989912.

43. Kaji MD, Geary TG, Beech RN. A Functional Comparison of Homopentameric Nicotinic Acetylcholine Receptors(ACR-16) Receptors From Necator americanus and Ancylostoma ceylanicum. Front Mol Neurosci. 2020; 13:601102. https://doi.org/10.3389/fnmol.2020.601102 PMID: 33324163.

44. Keiser J, Tritten L, Silbereisen A, Speich B, Adelfio R, Vargas M. Activity of oxantel pamoate monotherapy and combination chemotherapy against Trichuris muris and hookworms:revival of an old drug. PLoS Neglected Trop Dis. 2013; 7(3):e2119. https://doi.org/10.1371/journal.pntd.0002119 PMID: 23556013.

45. Callejón R, Cutillas $\mathrm{C}$, Nadler SA. Nuclear and mitochondrial genes for inferring Trichuris phylogeny. Parasitol Res. 2015; 114(12):4591-9. https://doi.org/10.1007/s00436-015-4705-7 PMID: 26341800.

46. Keiser J, Tritten L, Adelfio R, Vargas M. Effect of combinations of marketed human anthelmintic drugs against Trichuris muris in vitro and in vivo. Parasit Vectors. 2012; 5:292. https://doi.org/10.1186/17563305-5-292 PMID: 23231753.

47. Cowan N, Meier C, Neodo A, Keiser J. Exposure of Heligmosomoides polygyrus and Trichuris muris to albendazole, albendazole sulfoxide, mebendazole and oxantel pamoate in vitro and in vivo to elucidate the pathway of drug entry into these gastrointestinal nematodes. Int J Parasitol Drugs Drug Resist. 2017; 7(2):159-73. https://doi.org/10.1016/j.ijpddr.2017.03.005 PMID: 28371660.

48. Bjørn $\mathrm{H}$, Hennessy $\mathrm{DR}$, Friis $\mathrm{C}$. The kinetic disposition of pyrantel citrate and pamoate and their efficacy against pyrantel-resistant Oesophagostomum dentatum in pigs. Int J Parasitol. 1996; 26(12):1375-80. https://doi.org/10.1016/s0020-7519(96)00134-8 PMID: 9024887.

49. Kringel $\mathrm{H}$, Roepstorff $\mathrm{A}$. Trichuris suis population dynamics following a primary experimental infection. Vet Parasitol. 2006; 139(1-3):132-9. https://doi.org/10.1016/j.vetpar.2006.03.002 PMID: 16600510.

50. Pedersen S, Saeed I. Experimental infection of pigs with three dose levels of Trichuris suis. Parasite. 2000; 7(4):275-81. https://doi.org/10.1051/parasite/2000074275 PMID: 11147035.

51. Christensen CM, Barnes EH, Nansen P, Roepstorff A, Slotved HC. Experimental Oesophagostomum dentatum infection in the pig:worm populations resulting from single infections with three doses of larvae. Int J Parasitol. 1995; 25(12):1491-8. https://doi.org/10.1016/0020-7519(95)00085-2 PMID: 8719962.

52. Roepstorff A, Bjorn H, Nansen P, Barnes EH, Christensen CM. Experimental Oesophagostomum dentatum infections in the pig:worm populations resulting from trickle infections with three dose levels of larvae. Int J Parasitol. 1996; 26(4):399-408. https://doi.org/10.1016/0020-7519(96)00006-9 PMID: 8773527.

53. Hansen TVA, Nejsum P, Friis C, Olsen A, Thamsborg SM. Trichuris suis and Oesophagostomum dentatum show different sensitivity and accumulation of fenbendazole, albendazole and levamisole in vitro. PLoS Negl Trop Dis. 2014; 8(4):e2752. https://doi.org/10.1371/journal.pntd.0002752 PMID: 24699263.

54. Marti OG, Stewart TB, Hale OM. Comparative efficacy of fenbendazole, dichlorvos, and levamisole $\mathrm{HCl}$ against gastrointestinal nematodes of pigs. J Parasitol. 1978; 64(6):1028-31. PMID: 739296.

55. Jacobs DE, Lean IJ, Oakley GA. Levamisole:efficacy against Trichuris suis. Vet Rec. 1977; 100(3):49. https://doi.org/10.1136/vr.100.3.49 PMID: 835213.

56. Galtier $\mathrm{P}$, Escoula L, Alvinerie $\mathrm{M}$. Pharmacokinetics of $[3 \mathrm{H}]$ levamisole in pigs after oral and intramuscular administration. Am J Vet Res. 1983; 44(4):583-7. PMID: 6869955.

57. Tilney LG, Connelly PS, Guild GM, Vranich KA, Artis D. Adaptation of a nematode parasite to living within the mammalian epithelium. J Exp Zool Part A Comp Exp Biol. 2005; 303(11):927-45. https://doi. org/10.1002/jez.a.214 PMID: 16217807. 
58. Karadzovska D, Seewald W, Browning A, Smal M, Bouvier J, Giraudel JM. Pharmacokinetics of monepantel and its sulfone metabolite, monepantel sulfone, after intravenous and oral administration in sheep. J Vet Pharmacol Ther. 2009; 32(4):359-67. • https://doi.org/10.1111/j.1365-2885.2008.01052.x PMID: 19614841.

59. Lifschitz A, Ballent M, Virkel G, Sallovitz J, Viviani P, Lanusse C. Accumulation of monepantel and its sulphone derivative in tissues of nematode location in sheep:Pharmacokinetic support to its excellent nematodicidal activity. Vet Parasitol. 2014; 203(1-2):120-6. https://doi.org/10.1016/j.vetpar.2014.02. 049 PMID: 24647279.

60. Kaminsky R, Mosimann D, Sager H, Stein P, Hosking B. Determination of the effective dose rate for monepantel(AAD 1566) against adult gastro-intestinal nematodes in sheep. Int J Parasitol. 2009; 39 (4):443-6. https://doi.org/10.1016/j.ijpara.2008.09.009 PMID: 18950633.

61. Sager H, Hosking B, Bapst B, Stein P, Vanhoff K, Kaminsky R. Efficacy of the amino-acetonitrile derivative, monepantel, against experimental and natural adult stage gastro-intestinal nematode infections in sheep. Vet Parasitol. 2009; 159(1):49-54. https://doi.org/10.1016/j.vetpar.2008.10.006 PMID: 19019553.

62. U.S. Department of Health and Human Services, National Institutes of Health(NIH) National Center for Advancing Translational Sciences(NCATS). Derquantel [Internet]. [cited 11 Nov 2020]. Available: https://drugs.ncats.io/drug/OLOUGK6OOX

63. Moser W, Schindler C, Keiser J. Drug combinations against Soil-Transmitted Helminth infections. Adv Parasitol. 2019; 103:91-11. https://doi.org/10.1016/bs.apar.2018.08.002 PMID: 30878060.

64. Moser W, Sayasone S, Xayavong S, Bounheuang B, Puchkov M, Huwyler J, et al. Efficacy and tolerability of triple drug therapy with albendazole, pyrantel pamoate, and oxantel pamoate compared with albendazole plus oxantel pamoate, pyrantel pamoate plus oxantel pamoate, and mebendazole plus pyrantel pamoate and oxantel pamoate against hookworm infections in school-aged children in Laos:a randomised, single-blind trial. Lancet Infect Dis. 2018; 18(7):729-737. https://doi.org/10.1016/S1473-3099 (18)30220-2 PMID: 29673735.

65. Moser W, Coulibaly JT, Ali SM, Ame SM, Amour AK, Yapi RB, et al. Efficacy and safety of tribendimidine, tribendimidine plus ivermectin, tribendimidine plus oxantel pamoate, and albendazole plus oxantel pamoate against hookworm and concomitant soil-transmitted helminth infections in Tanzania and Côte d'Ivoire:a randomised, controlled, single-blinded, non-inferiority trial. Lancet Infect Dis. 2017; 17 (11):1162-1171. https://doi.org/10.1016/S1473-3099(17)30487-5 PMID: 28864027.

66. Barda B, Ame SM, Ali SM, Albonico M, Puchkov M, Huwyler J, et al. Efficacy and tolerability of moxidectin alone and in co-administration with albendazole and tribendimidine versus albendazole plus oxantel pamoate against Trichuris trichiura infections:a randomised, non-inferiority, single-blind trial. Lancet Infect Dis. 2018; 18(8):864-873. https://doi.org/10.1016/S1473-3099(18)30233-0 PMID: 29858149.

67. Schimmel A, Altreuther G, Schroeder I, Charles S, Cruthers L, Kok DJ, et al. Efficacy of emodepside plus praziquantel tablets(profender tablets for dogs) against mature and immature adult Trichuris vulpis infections in dogs. Parasitol Res. 2009; 105 Suppl 1:S17-22. https://doi.org/10.1007/s00436-009-1491. O PMID: 19575221.

68. Europeans Medicines Agency(EMA). Profender [Internet]. [cited 11 Nov 2020]. Available from: https:// www.ema.europa.eu/en/medicines/veterinary/EPAR/profender.

69. Karpstein T, Pasche V, Häberli C, Scandale I, Neodo A, Keiser J. Evaluation of emodepside in laboratory models of human intestinal nematode and schistosome infections. Parasit Vectors. 2019; 12 (1):226. https://doi.org/10.1186/s13071-019-3476-x PMID: 31088525.

70. Center for Disease Control and Prevention(CDC) - Trichuriasis-Resources for Health Professionals [Internet]. [cited 15 Nov 2020]. Available from: https://www.cdc.gov/parasites/whipworm/health_ professionals/index.html.

71. Europeans Medicines Agency(EMA). Panacur AquaSol | European Medicines Agency [Internet]. [cited 15 Nov 2020]. Available from: https://www.ema.europa.eu/en/medicines/veterinary/EPAR/panacuraquasol.

72. World Health Organization(WHO). Guidelines:preventive chemotherapy to control soil-transmitted helminth infections in at-risk population groups. Geneva, Switzerland;2017.

73. Hansen TVA, Williams AR, Denwood M, Nejsum P, Thamsborg SM, Friis C. Pathway of oxfendazole from the host into the worm: Trichuris suis in pigs. Int J Parasitol Drugs Drug Resist. 2017; 7(3):416-24. https://doi.org/10.1016/j.jpddr.2017.11.002 PMID: 29156431.

74. Altschul SF, Madden TL. Sch+ñffer AA, Zhang J, Zhang Z, Miller W, et al. Gapped BLAST and PSIBLAST:a new generation of protein database search programs. Nucleic Acids Res. 1997; 25(17):3389402. https://doi.org/10.1093/nar/25.17.3389 PMID: 9254694. 
75. Petersen TN, Brunak S, Von Heijne G, Nielsen H. SignalP 4.0:Discriminating signal peptides from transmembrane regions. Nat Methods 2011; 8(10):785-6. https://doi.org/10.1038/nmeth.1701 PMID: 21959131.

76. Krogh A, Larsson B, Von Heijne G, Sonnhammer ELL. Predicting transmembrane protein topology with a hidden Markov model:Application to complete genomes. J Mol Biol 2001; 305(3):567-80. https://doi. org/10.1006/jmbi.2000.4315 PMID: 11152613

77. Jespersen T, Grunnet M, Angelo K, Klærke DA, Olesen S-P. Dual-function vector for protein expression in both mammalian cells and Xenopus laevis oocytes. BioTechniques. 2002; 32(3):536-8. https://doi. org/10.2144/02323st05 PMID: 11911656.

78. Mello CC, Kramer JM, Stinchcomb D, Ambros V. Efficient gene transfer in C.elegans:extrachromosomal maintenance and integration of transforming sequences. EMBO J. 1991; 10(12):3959-70. PMID: 1935914. 